\title{
Zeitschrift für Anorganische und
}

Allgemeine Chemie

\section{Synthesis, Crystal Structure and Li Motion of $\mathrm{Li}_{8} \mathrm{SeN}_{2}$ and $\mathrm{Li}_{8} \mathrm{TeN}_{2}$}

\begin{tabular}{|r|l|}
\hline Journal: & Zeitschrift für Anorganische und Allgemeine Chemie \\
\hline Manuscript ID: & zaac.201000002.R1 \\
\hline Wiley - Manuscript type: & Article \\
\hline Date Submitted by the & 12 -Feb-2010 \\
\hline Complete List of Authors: & $\begin{array}{l}\text { Bräunling, Daniel; TU München, Chemie } \\
\text { Pecher, Oliver; MaxPlanckInstitut für Chemische Physik fester } \\
\text { Stoffe } \\
\text { Trots, Dmytro; Universität Bayreuth, Bayerisches Geoinstitut } \\
\text { Senyshyn, Anatoliy; Technische Universität Darmstadt, Fachbereich } \\
\text { Material und Geowissenschaften } \\
\text { Zherebtsov, Dmitry; South Ural State University } \\
\text { Haarmann, Frank; RWTH Aachen, Institut für Anorganische Chemie } \\
\text { Niewa, Rainer; Universität Stuttgart, Anorganische Chemie }\end{array}$ \\
\hline Keywords: & $\begin{array}{l}\text { Nitride, Lithium, Li motional processes, Solid state NMR } \\
\text { spectroscopy, Quantum mechanical calculations }\end{array}$ \\
\hline
\end{tabular}

\section{s) ScholaroNE" \\ Manuscript Central}




\section{Introduction}

Lithium nitride halides are already well investigated, with emphasis on phase formation, crystal structures and lithium ion mobility. Early investigations originated from Sattlegger and Hahn in the 1960s [1, 2]. In the meantime the compounds have attracted some attention as fast solid lithium ion conductors [3 - 6]. More recent investigations in these systems elucidate structures and structural relationships of compounds that can be described with the general composition $\mathrm{Li}_{3-2 y} \mathrm{~N}_{1-y} X_{y}$ with $X=\mathrm{Cl}, \mathrm{Br}$, I [7 - 15]. In general, the crystal structures can be understood as

The compounds $\mathrm{Li}_{8} E \mathrm{~N}_{2}$ with $E=\mathrm{Se}$, Te were obtained in form of orange microcrystalline powders from reactions of $\mathrm{Li}_{2} E$ with $\mathrm{Li}_{3} \mathrm{~N}$. Single crystal growth of $\mathrm{Li}_{8} \mathrm{SeN}_{2}$ additionally succeeded from Li. The crystal structures were refined using single crystal data $\left(I 4_{1} m d\right.$, No. $109, Z=4$, Se: $a=7.048(1) \AA, c=9.995(1) \AA$, Te: $a=7.217(1) \AA, c=10.284(1) \AA$ ). Both compounds crystallize as isotypes with an anionic substructure motif known from cubic Laves phases and Li distributed over four crystallographic sites in diffraction pattern recorded in the temperature range from $3 \mathrm{~K}$ to $300 \mathrm{~K}$ and $\mathrm{X}$-ray diffraction patterns using synchrotron radiation taken from $300 \mathrm{~K}$ to $1000 \mathrm{~K}$ reveal the structural stability of both compounds in the studied temperature range until decomposition.

* Institut für Anorganische Chemie, Universität Stuttgart, Pfaffenwaldring 55, 70569 Stuttgart, Germany

Fax. ++49(0)711/ 68564241

[a] Department Chemie, Technische Universität München, Lichtenbergstraße 4, 85747 Garching, Germany

[b] Max-Planck-Institut für Chemische Physik fester Stoffe, Nöthnitzer Straße 40, 01187 Dresden, Germany

c] Bayerisches Geoinstitut, Universität Bayreuth, Universitätsstraße 30, 95447 Bayreuth, Germany Universität Darmstadt, Petersenstraße 23, 64287 Darmstadt, Germany

[e] South Ural State University, Prospect Lenina 76, Chelyabinsk 454080, Russia

f] Institut für Anorganische Chemie, RWTH Aachen, Landoltweg 1, 52074 Aachen, Germany

g] Institut für Anorganische Chemie, Universität Stuttgart, Pfaffenwaldring 55, 70569 Stuttgart, Germany
Motional processes of Li atoms in the title compounds have been revealed by temperature dependent NMR spectroscopic investigations. Those are indicated by significant changes of the ${ }^{7} \mathrm{Li}$ NMR signals. Li motion starts for $\mathrm{Li}_{8} \mathrm{SeN}_{2}$ above $150 \mathrm{~K}$ while already being present in $\mathrm{Li}_{8} \mathrm{TeN}_{2}$ at this temperature. Quantum mechanical calculations of NMR parameters reveal clearly different environments of the $\mathrm{Li}$ atoms determined by the electric field gradient which are sensitive to the anisotropy of charge distribution at the nuclear sites. With respect to an increasing coordination number according to $2+1,3,3+1$, and 4 for $\operatorname{Li}(3)$, $\mathrm{Li}(4), \operatorname{Li}(2)$, and $\operatorname{Li}(1)$, respectively, the values of the electric field gradients decrease. Different environments of $\mathrm{Li}$ predicted by quantum mechanical calculations are confirmed by ${ }^{7} \mathrm{Li} \mathrm{NMR}$ frequency sweep experiments at low temperatures. products of acid-base reactions in which the framework structure of $\alpha-\mathrm{Li}_{3} \mathrm{~N}$ [16] is broken down to units of lower dimensionality. In comparison to the investigations on lithium nitride halides, the data on lithium nitride chalcogenides are extremely rare $[17,18]$. Here we present crystal structure analysis and thermal expansion for $\mathrm{Li}_{8} \mathrm{SeN}_{2}$ and $\mathrm{Li}_{8} \mathrm{TeN}_{2}$ in a wide range of temperatures obtained from $\mathrm{X}$-ray, synchrotron radiation and neutron diffraction data. Additionally, we have used solid state NMR spectroscopy to probe motional processes of $\mathrm{Li}$ atoms. Furthermore the $\mathrm{Li}$ bonding situation is investigated by combined application of quantum mechanical calculations and NMR experiments.

\section{Results and Discussion}

\section{Synthesis and composition determination}

To derive optimal reaction temperatures for the preparation of the title compounds $\mathrm{Li}_{8} \mathrm{SeN}_{2}$ and $\mathrm{Li}_{8} \mathrm{TeN}_{2}$ we first carried out several DTA measurements (Fig. 1). The reaction of $\mathrm{Li}$ with appropriate amounts of $\mathrm{Se}$ or Te for the formation of $\mathrm{Li}_{2} E(E=\mathrm{Se}, \mathrm{Te})$ in Ar atmosphere results in strongly exothermic reactions at $490 \mathrm{~K}$ and $691 \mathrm{~K}$, respectively. The reactions proceed well above the melting point of pure $\mathrm{Li}$, which can be taken from the measurements as endothermic effect at about $450 \mathrm{~K}$. The onset-temperature for the formation of $\mathrm{Li}_{2} \mathrm{Se}$ coincides with the melting point of Se $(494 \mathrm{~K})$, while the reaction with Te initiates some $30 \mathrm{~K}$ below the respective melting point of Te $(723 \mathrm{~K})$, corresponding to the formation of the eutectic melting 
temperature $\mathrm{LiTe}_{3}-\mathrm{Te}(696 \mathrm{~K})$. In comparison, the phase diagram of $\mathrm{Li}-\mathrm{Se}$ does not contain any eutectic with lower melting point than pure Se [19]. In both cases the reaction starts with a very sharp edge in the DTA-peak with no indication of a partial melting of Se or the Te containing eutectic, respectively, which should add some endothermic contribution. In a second series of experiments appropriate molar ratios of $\mathrm{Li}_{3} \mathrm{~N}$ were added to the mixtures of $\mathrm{Li}$ and $E$. The resulting DTA curve for $E=$ Se shows an exothermic chemical reaction starting even slightly below the melting point of pure $\mathrm{Li}$ and smeared out over a much broader temperature range. For $E=$ Te the reaction starts at a slightly higher temperature than observed for the binary case, but is similarly smeared out to higher temperatures. Since the reaction products contained significant amounts of the binary compounds next to the ternary products the higher preparation temperature of $1023 \mathrm{~K}$ was chosen to achieve complete reaction. The products were microcrystalline orange powders with a slightly darker color for the tellurium compound. Chemical analyses of the obtained powder samples revealed very minor impurities of oxygen and resulted in the following compositions: $\mathrm{Li}_{7.90(6)} \mathrm{Se}_{1.00(1)} \mathrm{N}_{2.05(6)} \mathrm{O}_{0.025(1)}(w(\mathrm{Li})=33.60 \pm 0.24 \%, w(\mathrm{Se})$ $=48.41 \pm 0.25 \%, w(\mathrm{~N})=17.62 \pm 0.51 \%, w(\mathrm{O})=0.25 \pm$ $0.01 \%)$ and $\mathrm{Li}_{8.03(6)} \mathrm{Te}_{1.00(1)} \mathrm{N}_{2.18(4)} \mathrm{O}_{0.0017(4)}(w(\mathrm{Li})=24.94 \pm$ $0.18 \%, w(\mathrm{Te})=57.07 \pm 0.61 \%, w(\mathrm{~N})=13.66 \pm 0.25 \%$, $w(\mathrm{O})=0.12 \pm 0.03 \%)$. Under the identical preparation conditions, but with an excess of Li single crystals of $\mathrm{Li}_{8} \mathrm{SeN}_{2}$ were obtained.

\section{Crystal chemistry}

For crystal structure refinements in-house X-ray powder patterns were indexed with tetragonal unit cells of $a=$ 7.060(2) $\AA, c=9.9689(7) \AA, V=496.85(9) \AA^{3}(\mathrm{Se}), a=$ 7.2127(3) $\AA, c=10.2793(4) \AA, V=534.76(2) \AA^{3}$ (Te). At this point it is worthwhile to point out that those cells are metrically quite close to cubic, particularly for $\mathrm{Li}_{8} \mathrm{SeN}_{2}$, however, the reflection splitting can be clearly observed on close inspection. We note, that a similar cubic unit cell was reported for $\mathrm{Li}_{7} \mathrm{IN}_{2}$ [2]. The structure of this iodide was described in space group $F \mathbf{\$} 3 m$ with a highly disordered Lisubstructure [15]. For the title compounds an analysis of the extinction conditions for X-ray powder as well as single crystal data led to the tetragonal space group $I 4_{1} /$ amd as the most likely choice. However, only the positions of the heavier anions could be determined from the X-ray diffraction data. $E$ and $\mathrm{N}$ realize the same motif as was deduced for $\mathrm{I}$ and $\mathrm{N}$ in $\mathrm{Li}_{7} \mathrm{IN}_{2}$. With the aim to localize all $\mathrm{Li}$ positions we performed neutron powder diffraction at ambient and lower temperatures down to $3 \mathrm{~K}$. Close inspections of the patterns revealed the presence of the reflection with Miller index (310). This reflection violates the extinction condition for the $a$-glide plane perpendicular to [001] $(h k 0: h=2 n)$, indicating $I 4_{1} m d$ as the correct space group choice. Apparently, the intensity contributions of $\mathrm{Li}$ in the neutron powder diffraction experiments produce this reflection $\left(b_{\mathrm{c}}(\mathrm{Li})=-1.90 \mathrm{fm} ; b_{\mathrm{c}}(\mathrm{N})=9.36 \mathrm{fm} ; b_{\mathrm{c}}(\mathrm{Se})=7.97\right.$ $\left.\mathrm{fm} ; b_{\mathrm{c}}(\mathrm{Te})=5.80 \mathrm{fm}[20]\right)$ which has too low intensity to be observed in X-ray powder diffraction due to the small scattering contribution of $\mathrm{Li}$. In other words, the anionic substructure is (approximately) centrosymmetric, while the $\mathrm{Li}$-substructure is acentric. With this information the positional parameters of all atoms could be deduced from geometric considerations and refined against both powder diffraction patterns and single crystal X-ray diffraction data.
Tabs. 1 and 2 gather crystallographic and technical data for the structure determination of $\mathrm{Li}_{8} \mathrm{SeN}_{2}$ from single crystal $\mathrm{X}$-ray diffraction. Tabs. 3 and 4 present the respective data for simultaneous Rietveld refinements of X-ray and neutron powder patterns at ambient temperature for both compounds and for neutron diffraction patterns at $3 \mathrm{~K}$. Fig. 2 graphically depicts exemplarily the results of the Rietveld refinements for $\mathrm{Li}_{8} \mathrm{TeN}_{2}$ based on simultaneous treatment of X-ray and neutron powder diffraction patterns taken at $300 \mathrm{~K}$. Refinement data on neutron diffraction patterns for further temperatures are available as supplementary data. After those structure refinements were finished it came to our knowledge, that neutron powder diffraction at ambient temperature had earlier been carried out in the frame of a habilitation thesis [17]. The resulting structural data are nearly identical.

According to our structure refinements $\mathrm{Li}_{8} \mathrm{SeN}_{2}$ and $\mathrm{Li}_{8} \mathrm{TeN}_{2}$ are isotypes. In the following we will discuss the structure peculiarities by using the distances from simultaneous X-ray and neutron powder diffraction, since the positions of $\mathrm{Li}$ should be more precisely determined. For sake of simplification we use the distances in $\mathrm{Li}_{8} \mathrm{TeN}_{2}$, the corresponding distances for $\mathrm{Li}_{8} \mathrm{SeN}_{2}$ can be taken from Tab. 5. Fig. 3 utilizes anisotropic displacement parameters from the single crystal diffraction refinement to emphasize the displacement of Li atoms.

The anionic substructure of $\mathrm{N}$ and $E$ resembles the atomic arrangement in cubic Laves phases, e.g., $\mathrm{MgCu}_{2}$. $\mathrm{N}$ occupies the position of $\mathrm{Cu}$ leading to a three-dimensional framework of vertex-sharing (empty) tetrahedra (Fig. 4). These tetrahedra are significantly distorted with edge lengths in the range of $3.3175(5) \AA$ to $3.8736(5) \AA$. The chalcogenide atoms are localized in the large voids of this frame within so-called Friauf polyhedra.

Li atoms fill the space within the anionic framework leading to the quite high coordination number of 9 for nitrogen (for comparison in $\alpha-\mathrm{Li}_{3} \mathrm{~N}$ : $C N(\mathrm{~N})=8$ [16], for the modifications at higher pressures $\beta-\mathrm{Li}_{3} \mathrm{~N}: C N(\mathrm{~N})=11, \gamma-$ $\left.\mathrm{Li}_{3} \mathrm{~N}: C N(\mathrm{~N})=6+8[21]\right)$ in a distorted capped quadratic antiprism. The interatomic distances are with $d(\mathrm{Li}-\mathrm{N})=$ $2.090(6) \AA-2.225(6) \AA$ slightly longer than in $\alpha-\mathrm{Li}_{3} \mathrm{~N}$, which can be easily rationalized from the different coordination numbers for $\mathrm{N}$. Under consideration of $\mathrm{Li}-\mathrm{Te}$ distances $d(\mathrm{Li}-\mathrm{Te})<3 \AA$ for the first coordination sphere $\left(\mathrm{Li}_{2} \mathrm{Te}: d(\mathrm{Li}-\mathrm{Te})=2.82 \AA\right.$ [22] $) \mathrm{Te}$ is coordinated by $9 \mathrm{Li}$ in a capped tetragonal cuboid (Fig. 5). However, the surrounding of the four crystallographic positions of $\mathrm{Li}$ are largely different (Fig. 3): considering the same maximum distances $d(\mathrm{Li}-\mathrm{Te})<3 \AA \mathrm{Li}(1)$ is tetrahedrally coordinated by $2 \mathrm{~N}$ and $2 \mathrm{Te}$ and $\mathrm{Li}(2)$ is in trigonal somewhat nonplanar coordination by $\mathrm{N}$ (angular sum $341.5^{\circ}$ ) completed by a Te at a clearly longer distance of 3.24(1) $\AA$. The surrounding of $\mathrm{Li}(4)$ is trigonal planar formed by two $\mathrm{N}$ and one Te. Different from those environments is the $\operatorname{Li}(3)$ coordination by two $\mathrm{N}$ with a bonding angle of $154.13(3)^{\circ}$. This two-fold coordination is indicated by distances below 2 $\AA$ and the longer distance to Te of 3.19(1) $\AA$. As is also indicated by quantum mechanical calculations and NMR spectroscopic investigations this arrangement leads to a clearly different bonding situation as compared to the three other Li sites (cf. NMR part). 
The relation to the cubic Laves phase $\mathrm{MgCu}_{2}$ can be most comfortably be derived in terms of a group-subgroup scheme after Bärnighausen [23] as is depicted in Fig. 6. Starting from the space group type $F d \overline{3} m$ of the Laves phase $\mathrm{MgCu}_{2}$ the tetragonal space group $I_{1} /$ amd results from a translationsgleiche symmetry reduction with index 3 with $a$ ' $=(a-b) / 2, \quad b^{\prime}=(a+b) / 2, \quad c^{\prime}=c$. A second translationsgleiche reduction with index 2 leads to the noncentrosymmetric space group $I 4_{1} m d$ and the respective positions of the anions in $\mathrm{Li}_{8} E \mathrm{~N}_{2}$.

The crystal structure of the title compounds resemble that of the structure family of Argyrodites (mineral $\mathrm{Ag}_{8} \mathrm{GeS}_{6}$ [24]). In the cubic high-temperature phases (space group $F \mathbf{4} 3 m$ ) of Argyrodites the chalcogenide realizes the motif a three-dimensional tetrahedral network of edge-sharing tetrahedra in the arrangement of $\mathrm{Cu}$ in the cubic Laves phase $\mathrm{MgCu}_{2}$. However, these tetrahedra are partly filled by $\mathrm{Ge}$ leading to a stacking of tetrahedra $\mathrm{GeS}_{4}$ and further $\mathrm{S}$. Argyrodites are extremely flexible in their compositions. They may be described with the general formula $A_{(12-n)} B^{n+} E^{2-}{ }_{(6-y)} X_{y}^{-}$with e.g. $A=\mathrm{Li}, \mathrm{Cu}, \mathrm{Ag} ; B=\mathrm{P}, \mathrm{As}, \mathrm{Si}$, $\mathrm{Ge} ; E=\mathrm{S}, \mathrm{Se} ; X=\mathrm{Cl}, \mathrm{Br}$, I and generally are known as $\mathrm{Cu}-$, Ag- and Li-ionic conductors [25, 26].

A number of cubic Laves phases are able to intercalate significant amounts of hydrogen under preservation of the general structural motif of the metal atoms although undergoing crystallographic symmetry reductions [27]. In the context of the title compounds it is particularly interesting to compare with the hydrogen-rich compounds $\mathrm{LaMg}_{2} \mathrm{D}_{7}, \mathrm{CeMg}_{2} \mathrm{D}_{7}$ [28] and $\mathrm{SmMg}_{2} \mathrm{D}_{7}$ [29]. Upon hydride formation the cubic Laves phases distort to tetragonal metric with space group $P 4_{1} 2_{1} 2$. In the resulting crystal structures the deuterium occupies positions in trigonal planar and tetrahedral coordination by either exclusively $\mathrm{Mg}$ or rareearth metal and $\mathrm{Mg}$. However, one crystallographic site is situated in the tetrahedra formed by $\mathrm{Mg}$. This position is unoccupied in $\mathrm{Li}_{8} E \mathrm{~N}_{2}$ (while it is partly occupied by Ge in the aforementioned Argyrodites). Nevertheless, the rareearth metal in the deuterides is higher coordinated by $\mathrm{D}$ (twelve-fold) than $E$ by $\mathrm{Li}$ in the title compounds (ninefold). On the other hand $\mathrm{Mg}$ is seven-fold and $\mathrm{N}$ nine-fold coordinated, respectively. This example underlines the structural stability of the Laves phase arrangement if a reasonable radii ratio is provided together with an extremely high structural variety for intercalation of small atoms.

\section{Temperature dependent diffraction experiments}

Since the displacement parameters of particularly $\mathrm{Li}$ at room temperature are comparably large we have studied the crystal structures of the title compounds additionally by neutron diffraction at $3,50,100,150,200,250 \mathrm{~K}$ to derive a reliable structure model. No indication for a structural transition was observed in these measurements. This finding agrees with the fact that DSC measurements in the temperature range of $175 \mathrm{~K}-670 \mathrm{~K}$ did not show any significant signal possibly related to a phase transition. On cooling the cla ratio monotonically decreases, however, the ideal value of $\sqrt{ } 2$ for a cubic metric is not reached even at $3 \mathrm{~K}$ (Figs. 7 and 8). Fig. 9 shows the temperature dependence of the isotrope displacement parameters as exclusively derived from these neutron diffraction experiments. Besides some scatter, all displacement parameters shrink with decreasing temperature. However, extrapolation of the values for $\mathrm{N}$ and $E$ to zero $\mathrm{K}$ results in small but finite values. The extrapolated displacement parameters for the different sites occupied by $\mathrm{Li}$ give quite large values indicating a significant static contribution additional to the vibration dominating at higher temperatures.

High-resolution powder diffraction studies at elevated temperatures up to $1000 \mathrm{~K}$ were carried out applying synchrotron radiation. Again the data indicate no structural transition in the studied temperature range in agreement with DSC measurements. At ambient temperatures the curves nearly coincide with those from neutron powder diffraction with only a small offset. With increasing temperature the unit cell parameters monotonically increase (Figs. 7 and 8). However, above $500 \mathrm{~K}$ the $c / a$ ratio exhibits a kink to a different slope followed by a maximum at $700 \mathrm{~K}$ and a decreasing ratio at higher temperatures. At such high temperatures the title compounds slowly decompose under formation of $\mathrm{Li}_{2} E$, the unit cell volume of $\mathrm{Li}_{8} E \mathrm{~N}_{2}$ determined at room temperature after the heating circle is slightly smaller than the initial volume indicating a slight change of composition. Simultaneously, the colors of the samples slightly darken. $\mathrm{Li}_{8} E \mathrm{~N}_{2}$ expands quite normally under heating up to $\sim 800 \mathrm{~K}$ and expansion increases in the range where the second phase appears. Relative expansion parameters along the $a$ - and $c$-axes indicate a nearly isotropic behavior in the studied temperature range until onset of decomposition.

\section{NMR spectroscopy and quantum mechanical calculations}

To study the chemical bonding of the different $\mathrm{Li}$ atoms in $\mathrm{Li}_{8} \mathrm{SeN}_{2}$ and $\mathrm{Li}_{8} \mathrm{TeN}_{2} \mathrm{NMR}$ spectroscopy in combination with quantum mechanical calculations was applied. This approach was successfully used in the past for various classes of compounds [30 - 32]. Since the title compounds are electrically non-conducting, chemical shielding $(\delta)$ and electric field gradient (EFG) can be calculated with quantum mechanical methods [33 - 35]. This allows an estimation of the expected NMR signals and provides information about the bonding situation of the atoms.

The results of the quantum mechanical calculations of NMR parameters for the structure models obtained via neutron powder diffraction at $3 \mathrm{~K}$ and the geometrically optimized structures of $\mathrm{Li}_{8} \mathrm{SeN}_{2}$ and $\mathrm{Li}_{8} \mathrm{TeN}_{2}$ are very similar for both compounds (Tab. 6). The bonding situations of the Li atoms at the four different sites apparently differ since their EFGs vary considerably. A visualization of the EFGs as ellipsoids with respect to their environment is depicted exemplarily for $\mathrm{Li}_{8} \mathrm{TeN}_{2}$ in Fig. 10. To emphasize the orientation of the tensors which for powder samples can only be obtained by quantum mechanical calculations the directions of the three principal axes $V_{\text {ii }}$ are indicated. No significant differences of the orientations were obtained for $\mathrm{Li}_{8} \mathrm{SeN}_{2}$ indicating a high similarity of the bonding situation of the $\mathrm{Li}$ atoms in both compounds. The sizes of the ellipsoids corresponding to the anisotropy of the charge distribution at the nuclear sites clearly decrease with increasing coordination number according to $C N=2+1,3$, $3+1$, and 4 for $\operatorname{Li}(3), \operatorname{Li}(4), \operatorname{Li}(2)$, and $\operatorname{Li}(1)$, respectively. The large EFG of $\mathrm{Li}(3)$ indicates an outstanding anisotropy of the charge distribution compared to the other $\mathrm{Li}$ atoms. For comparison the EFGs in $\alpha-\mathrm{Li}_{3} \mathrm{~N}$ determined by NMR experiments are $0.58 \mathrm{MHz}$ and $0.28 \mathrm{MHz}$ for the two-fold 
and the three-fold coordinated Li atoms, respectively [36]. Quantum mechanical calculations are in good agreement with these results. The origin of the EFGs was attributed to a polarization of the charge distribution of the Li atoms [30]. This polarization induced by chemical bonding can also be expected to be the largest for $\mathrm{Li}(3)$ in $\mathrm{Li}_{8} \mathrm{SeN}_{2}$ and $\mathrm{Li}_{8} \mathrm{TeN}_{2}$ since the $\mathrm{Li}-\mathrm{N}$ distances of $1.955(8) \AA$ and $1.990(3) \AA$, respectively, are significantly shorter than for the other $\mathrm{Li}$ atoms (Tab. 5). This corresponds to the situation in $\alpha-\mathrm{Li}_{3} \mathrm{~N}$ with $1.939 \AA$ and $2.130 \AA$ for the two-fold and three-fold coordinated $\mathrm{Li}$ atoms, respectively [16]. Considering the different values of the EFGs of the title compounds the $\mathrm{Li}$ environments might be distinguishable by NMR experiments.

The non-referenced calculated isotropic chemical shifts $\left(\delta_{\text {iso }}\right)$ are quite similar for all $\mathrm{Li}$ atoms, thus it can not be expected to resolve separated NMR signals experimentally. With respect to the anisotropy of chemical shielding $\left(\delta_{\text {aniso }}\right)$ $\mathrm{Li}(3)$ also differs from the other $\mathrm{Li}$ indicating an exceptional bonding situation of $\mathrm{Li}(3)$ (Tab. 6).

The static and magic angle spinning (MAS) ${ }^{7} \mathrm{Li}$ NMR signals of $\mathrm{Li}_{8} \mathrm{SeN}_{2}$ and $\mathrm{Li}_{8} \mathrm{TeN}_{2}$ recorded at ambient temperature are depicted in Fig. 11. The full spectral width of the signals indicates the presence of quadrupole coupling being due to interactions of the EFG at the nuclear sites with the nuclear quadrupole moments. This can also be seen by the number of rotational side bands of the MAS NMR signals. The main transition in the centre of the signal is almost symmetric and covers a comparably small frequency range being in agreement with simulations of the NMR signals based on the quantum mechanical calculations. The individual signal contributions can not be resolved by application of MAS, but the average isotropic chemical shift can be determined (see Tab. 6 and inset of Fig. 11).

To investigate motional processes of the $\mathrm{Li}$ atoms temperature dependent NMR experiments were performed. The full width at half maximum (FWHM) of the NMR signals for both compounds differs significantly at ambient temperature (Fig. 11 inset). Assuming dipole-dipole coupling to be the dominant mechanism of the NMR signal line broadening this already indicates motional processes of the $\mathrm{Li}$ atoms which average the coupling. The temperature dependence of the FWHM and the corresponding ${ }^{7} \mathrm{Li} \mathrm{NMR}$ signals show a dramatic change of the NMR signal line shape (Fig. 12). At low temperatures the main transition signal is broadened and the satellite transitions are clearly visible, resulting in an elaborated line shape of the NMR signals. At high temperatures only a narrow NMR signal remains for both compounds. The change of the NMR signal line shape indicates an averaging of the quadrupole coupling in addition. A continuous decrease of the FWHM of the main transition NMR signal with increasing temperature is observed for $\mathrm{Li}_{8} \mathrm{SeN}_{2}$ and $\mathrm{Li}_{8} \mathrm{TeN}_{2}$ (Fig. 12 insets). In contrast a dramatic reduction of the FWHM resulting from a spontaneous onset of $\mathrm{Li}$ diffusion accompanied by a phase transition is reported e.g. for the Argyrodite $\mathrm{Li}_{6} \mathrm{PS}_{5} \mathrm{I}[37,38]$. The continuous change of the FWHM for the title compounds evidences the absence of a phase transition of the title compounds being in agreement with the diffraction experiments.

The decrease of the signal width with temperature differs for $\mathrm{Li}_{8} \mathrm{SeN}_{2}$ and $\mathrm{Li}_{8} \mathrm{TeN}_{2}$ (Fig. 12 insets). While for $\mathrm{Li}_{8} \mathrm{SeN}_{2}$ a constant signal width seems to be reached below $150 \mathrm{~K}$ it is not yet clear for which temperature a constant FWHM of the $\mathrm{Li}_{8} \mathrm{TeN}_{2}$ NMR signals is reached since the values decrease with increasing temperature in the investigated temperature range. Additional NMR measurements of the FWHM at lower temperatures are required for this purpose. Above $350 \mathrm{~K}$ and $450 \mathrm{~K}$ a constant signal width is observed for $\mathrm{Li}_{8} \mathrm{SeN}_{2}$ and $\mathrm{Li}_{8} \mathrm{TeN}_{2}$, respectively. This indicates differences of the motional processes of the $\mathrm{Li}$ atoms for both compounds.

In order to resolve the different ${ }^{7} \mathrm{Li}$ NMR signal contributions and to ensure that the motional processes of the $\mathrm{Li}$ atoms are frozen, frequency sweep NMR experiments were performed at $15 \mathrm{~K}$ (Fig. 13). Remarkably different NMR line shapes for both compounds are observed at this temperature. While the NMR signal of $\mathrm{Li}_{8} \mathrm{TeN}_{2}$ is well elaborated showing clearly the features of the individual signal contributions, the signal of $\mathrm{Li}_{8} \mathrm{SeN}_{2}$ is smeared out and characteristic features of the signal contributions are only weekly indicated. This difference points at a high level of residual disorder in $\mathrm{Li}_{8} \mathrm{SeN}_{2}$ and is confirmed by detailed line shape analysis of the NMR signals. Using the results of the quadrupole coupling parameters obtained by the quantum mechanical calculations as a starting model the experimental values were quantified by least-squares fits of the NMR signals (Tab. 6). Both NMR experiments and quantum mechanical calculations are in good agreement confirming experimentally the anisotropy of the charge distribution in the vicinity of the nuclear sites of the $\mathrm{Li}$ atoms determined by quantum mechanical methods.

\section{Concluding remarks}

The title compounds show Li-motional processes according to solid state NMR spectroscopy. An anomalous thermal expansion in non-ion conducting phases, which precedes a transition to an ion conducting phase, seems to be characteristic for some solid ion conductors (see [39] and references therein), in particular when they undergo an abrupt transition into the ion conducting state. The compounds $\mathrm{Li}_{8} E \mathrm{~N}_{2}(E=\mathrm{Se}, \mathrm{Te})$ do not suffer any clearly recognizable transition in the full temperature range from $3 \mathrm{~K}$ to close to $800 \mathrm{~K}$ according to diffraction data. The observation of Li motion by NMR spectroscopy without a sharp structural transformation to an ion conducting phase could imply that $\mathrm{Li}_{8} \mathrm{TeN}_{2}$ and $\mathrm{Li}_{8} \mathrm{SeN}_{2}$ are type II or type III ion conductors according to classification by Keen [40].

The anisotropy of the charge distribution of the Li atoms differs considerably for the four crystallographic sites in $\mathrm{Li}_{8} E \mathrm{~N}_{2}$ with $E=\mathrm{Se}$ and Te, respectively. A clear correlation of the anisotropy of the charge distribution and the coordination number of the $\mathrm{Li}$ atoms is recognized. Good agreement of NMR experiments and quantum mechanical calculations of NMR parameters is obtained. 

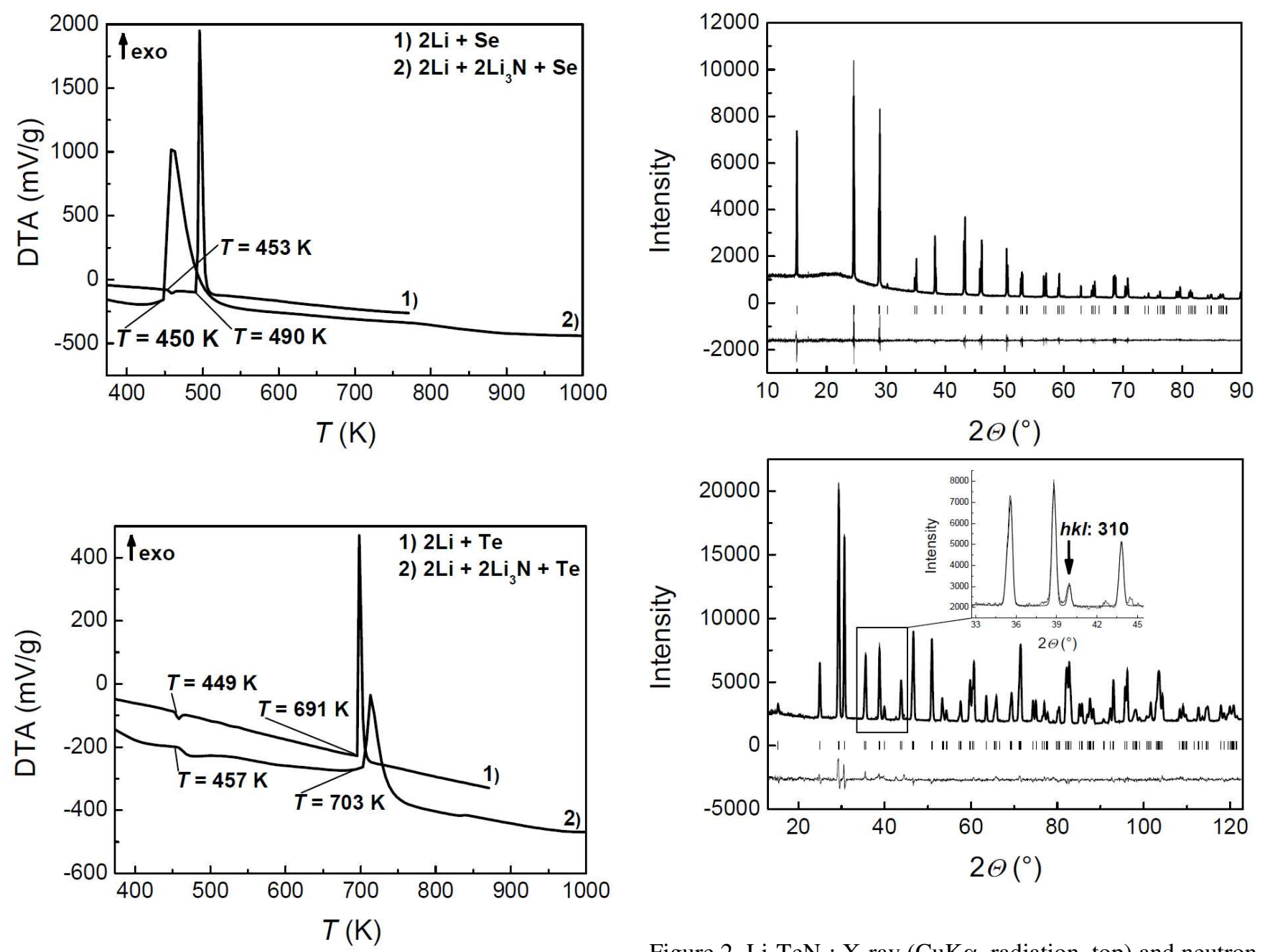

Figure 1. DTA diagrams of reactions of (1) Li with $E$ and (2) Li, $E$ with $\mathrm{Li}_{3} \mathrm{~N}$ (top: $E=\mathrm{Se}$, bottom: $E=\mathrm{Te}$ ).

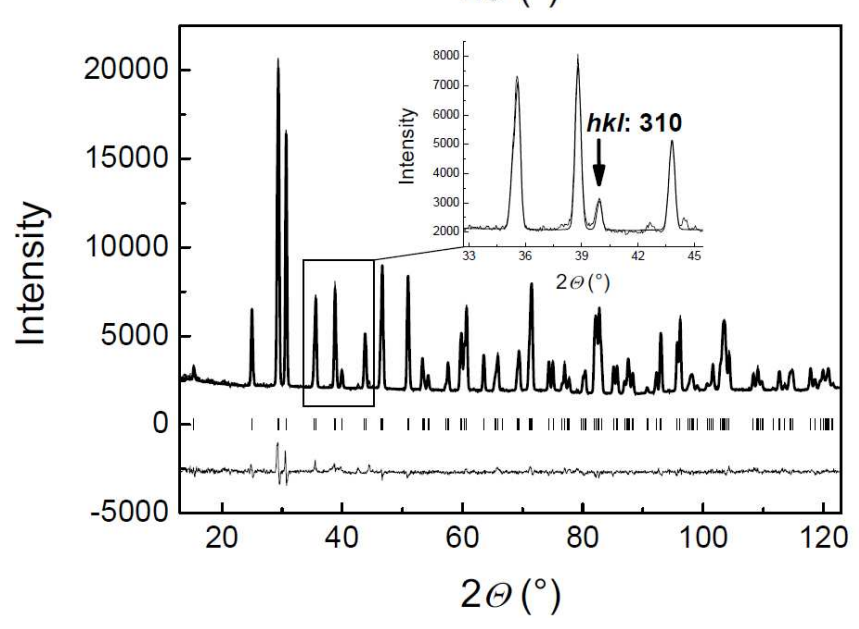

Figure 2. $\mathrm{Li}_{8} \mathrm{TeN}_{2}$ : $\mathrm{X}$-ray $\left(\mathrm{CuK} \alpha_{1}\right.$ radiation, top) and neutron $(\lambda=1.5482 \AA$, bottom) powder diffraction diagrams. The measured data are shown as points, the continuous line represents the calculated profile and the lower line shows the difference between the calculated and observed intensities. Marks below the data indicate positions of calculated Bragg reflections. The inset enlarges the reflection (310) calling for the space group choice $I 4_{1} m d$ rather than $I 4_{1} /$ amd (low intensity reflections at 2 theta of about $42.8^{\circ}$ and $44.8^{\circ}$ are due to a minor unknown impurity). 


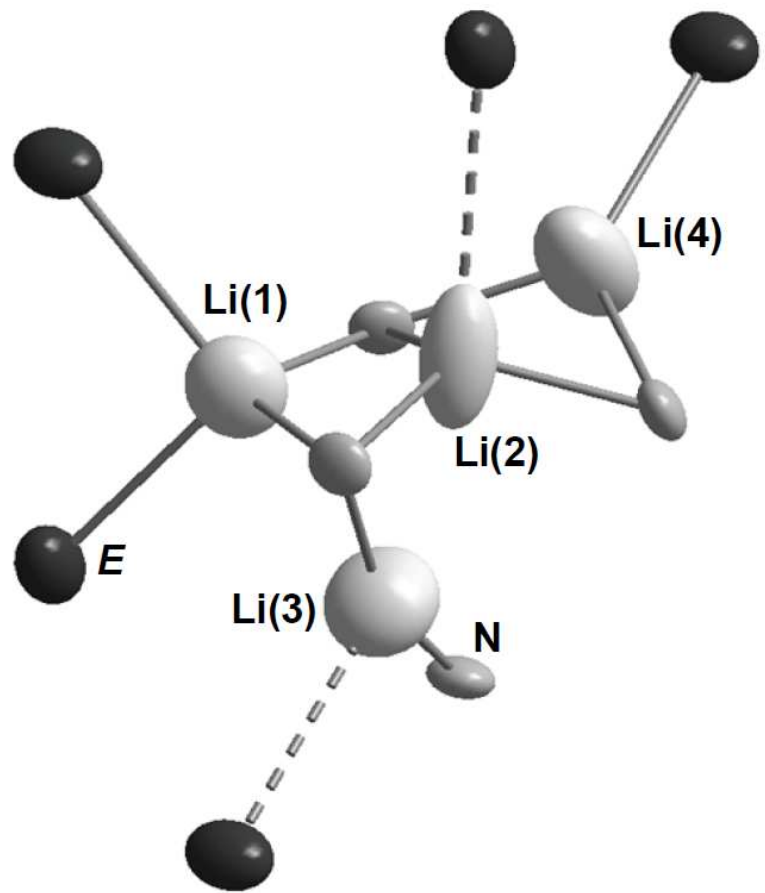

Figure 3. $\mathrm{Li}_{8} \mathrm{SeN}_{2}$ : Coordination of $\mathrm{Li}$ (large grey ellipsoids) by $\mathrm{N}$ (smaller grey ellipsoids) and Se (dark ellipsoids). Interatomic distances $>3 \AA$ are indicated by dashed lines. Anisotropic displacement ellipsoids are taken from the single crystal X-ray data and depicted with $99 \%$ probability.

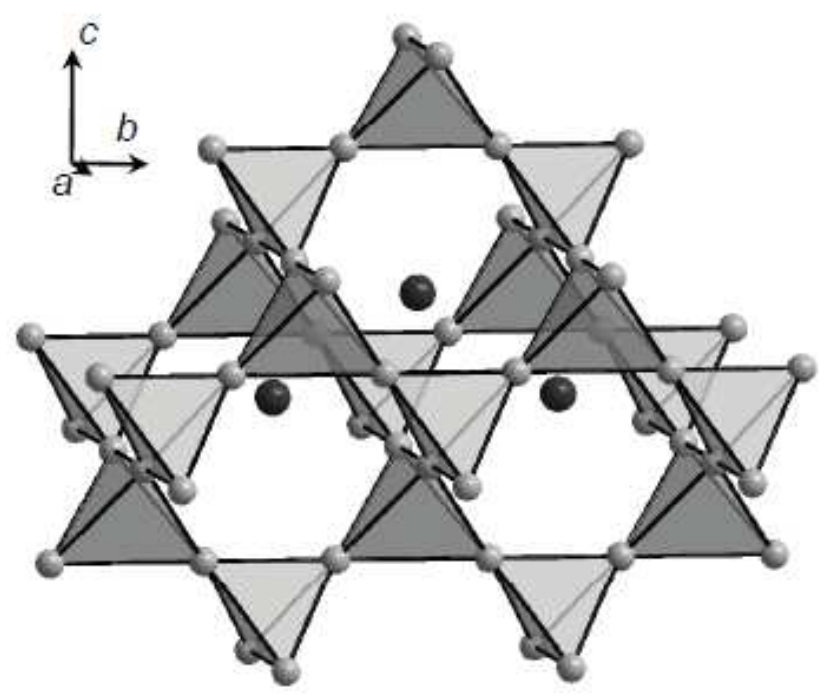

Figure 4. $\mathrm{Li}_{8} E \mathrm{~N}_{2}$ : Chalcogenide ions $E=\mathrm{Se}$, Te (dark spheres) embedded in a framework of vertex-sharing (empty) tetrahedra of $\mathrm{N}$ (light grey spheres) with the structural motif of a cubic Laves phase.

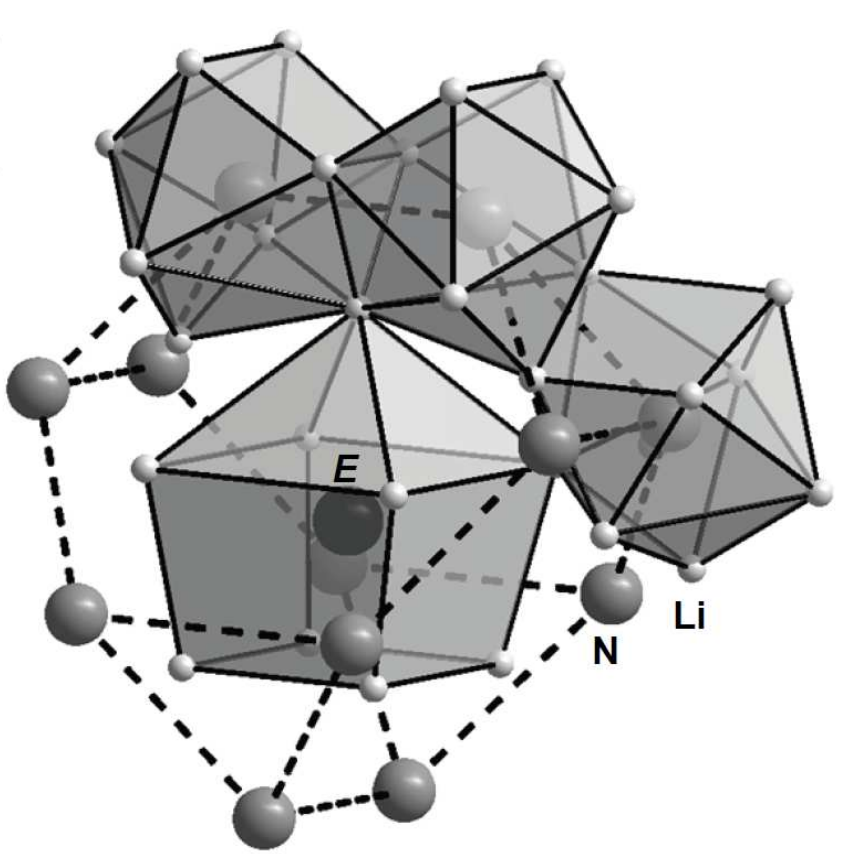

Figure 5. $\mathrm{Li}_{8} E \mathrm{~N}_{2}$ : Capped cuboid as first coordination environment of $E=\mathrm{Se}$, Te (dark spheres) by Li (small light grey spheres). The second coordination (Friauf polyhedron) formed by N (larger grey spheres) is indicated by dashed lines. Exemplarily, the coordination of three $\mathrm{N}$ by $\mathrm{Li}$ in form of distorted capped square anti-prisms given. 


\section{Page 7 of 36}

2

3

4

5

6

7

8

9

10

11

12

13

14

15

16

17

18

19

20

21

22

23

24

25

26

27

28

29

30

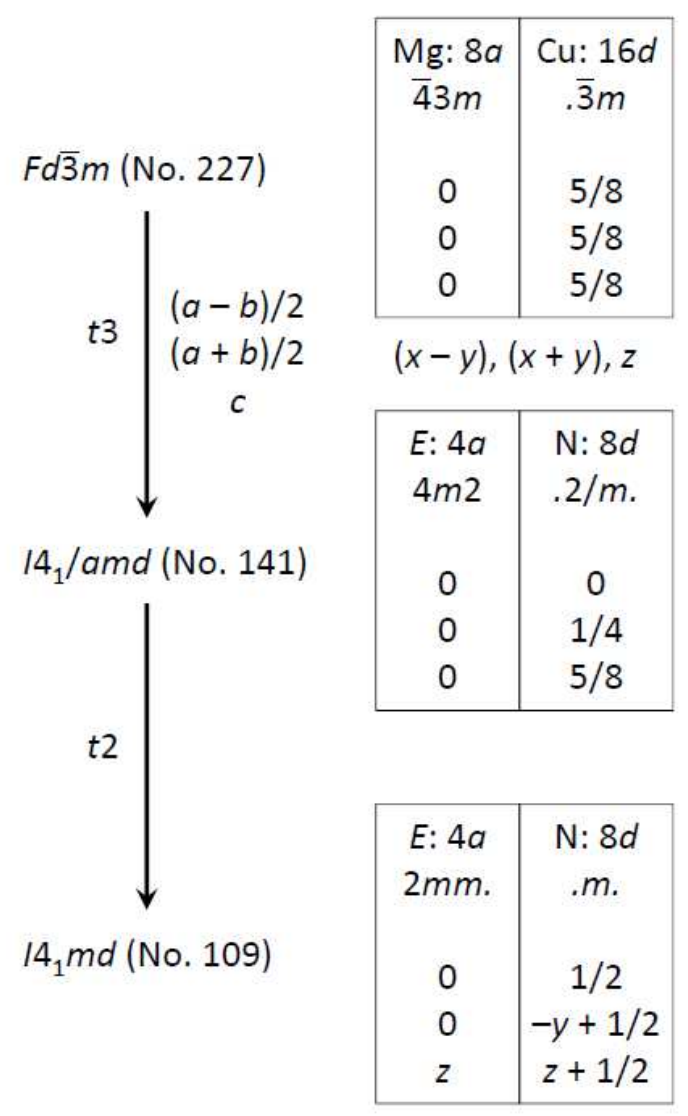

Figure 6. $\mathrm{Li}_{8} E \mathrm{~N}_{2}$ : Group-subgroup scheme [23] for the anionic substructure derived from the cubic Laves phase $\mathrm{MgCu}_{2}$. The left part represents the symmetry reduction (translationsgleiche $(t)$ and index) and unit cell transformation. The relationship between the atomic coordinates is shown on the right. 

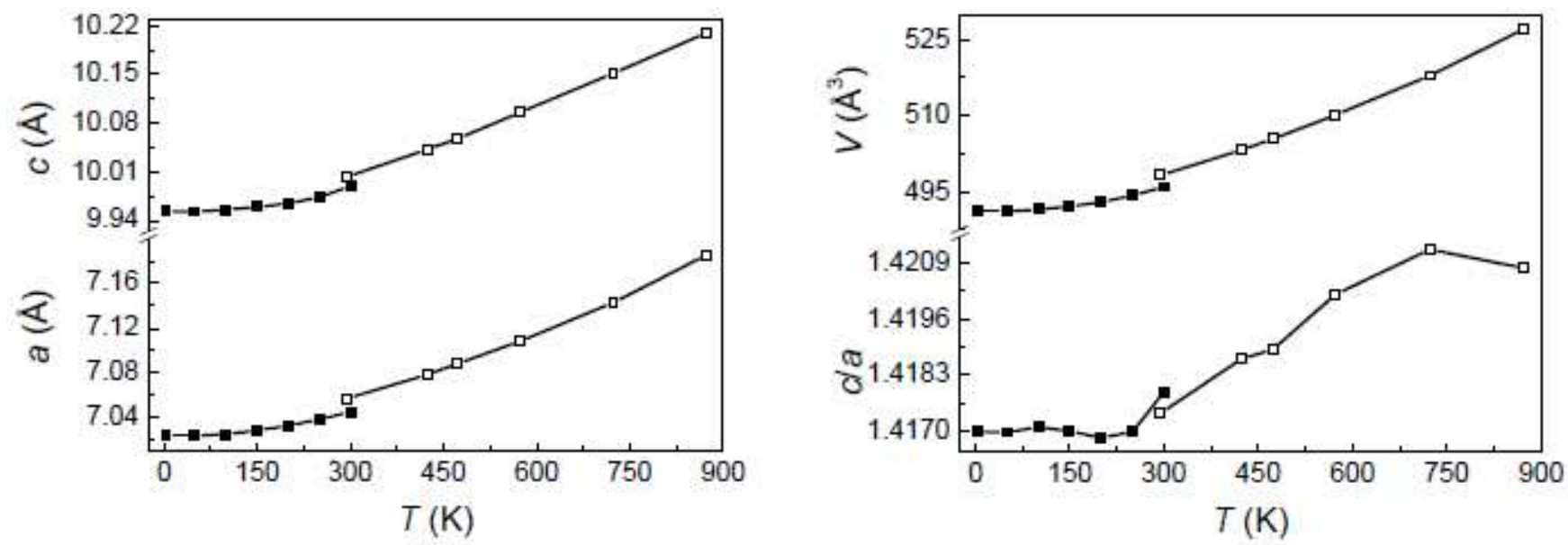

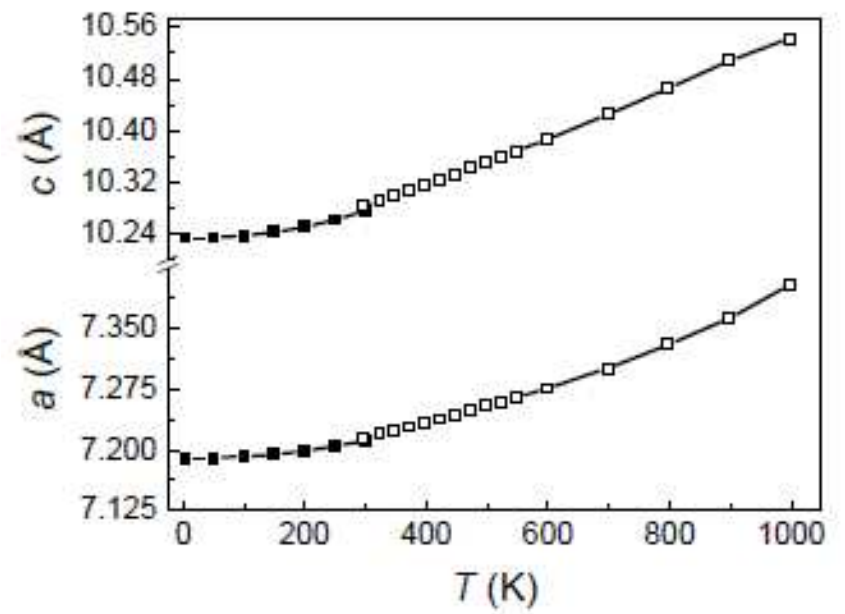

Figure 7. $\mathrm{Li}_{8} E \mathrm{~N}_{2}$ : Temperature dependence of the unit cell parameters $a$ and c from neutron powder diffraction (full symbols) and from high resolution X-ray powder diffraction using synchrotron radiation (open symbols) for top: $E=\mathrm{Se}$, and bottom: $E=\mathrm{Te}$.

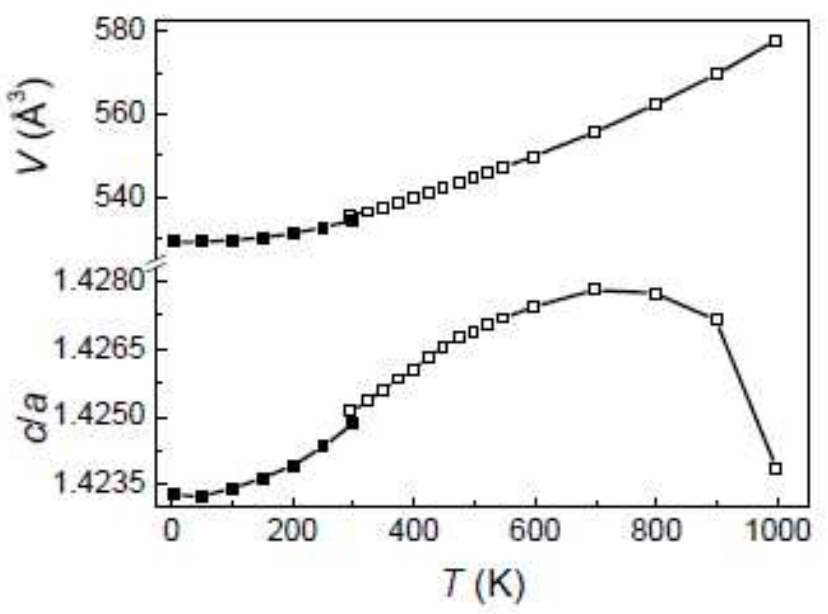

Figure 8. $\mathrm{Li}_{8} E \mathrm{~N}_{2}$ : Temperature dependence of the unit cell volume $V$ and the ration $c / a$ from neutron powder diffraction (full symbols) and from high resolution X-ray powder diffraction using synchrotron radiation (open symbols) for top: $E=\mathrm{Se}$, and bottom: $E=\mathrm{Te}$. 


\section{Page 9 of 36}
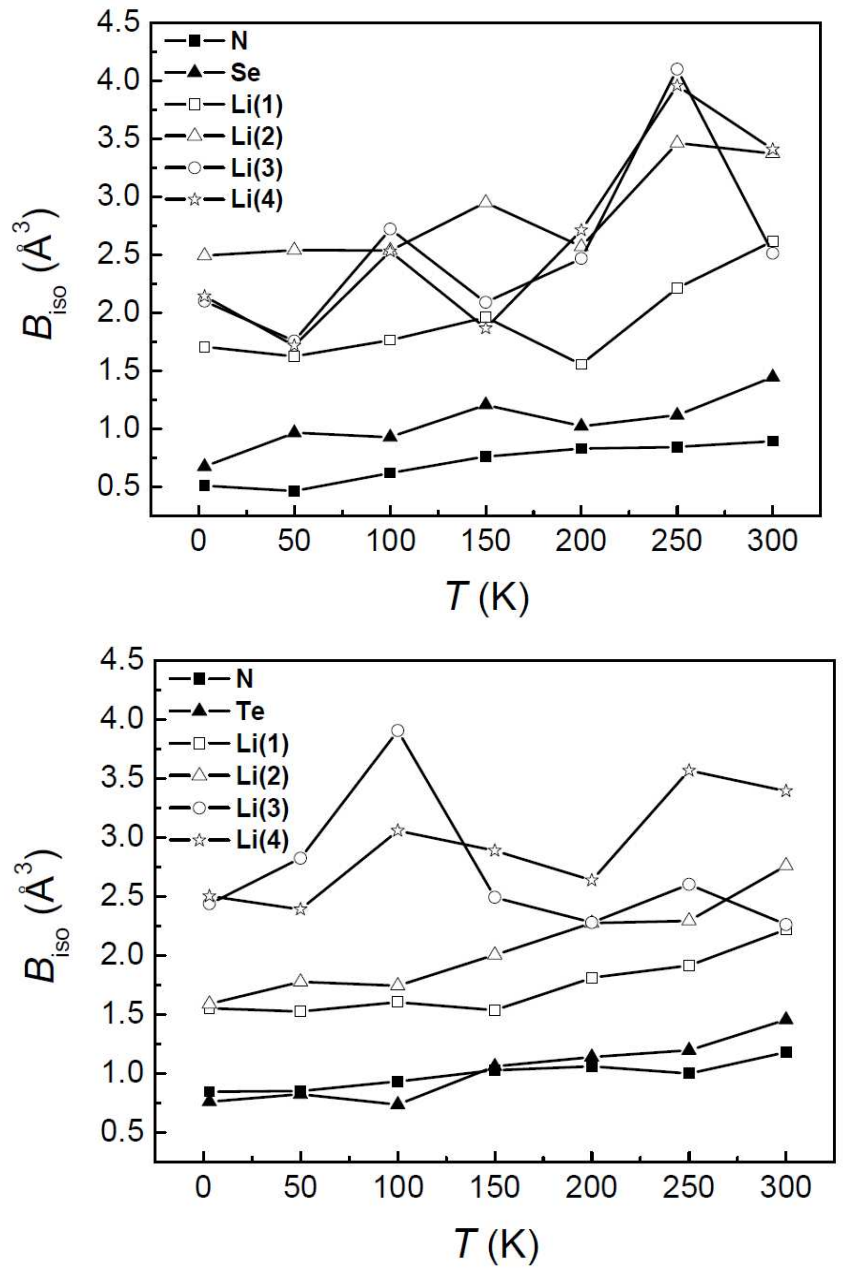

Figure. 9. $\mathrm{Li}_{8} E \mathrm{~N}_{2}$ : Temperature dependence of the isotropic displacement parameters from neutron powder diffraction (top: $E=\mathrm{Se}$, and bottom: $E=\mathrm{Te}$ ). 


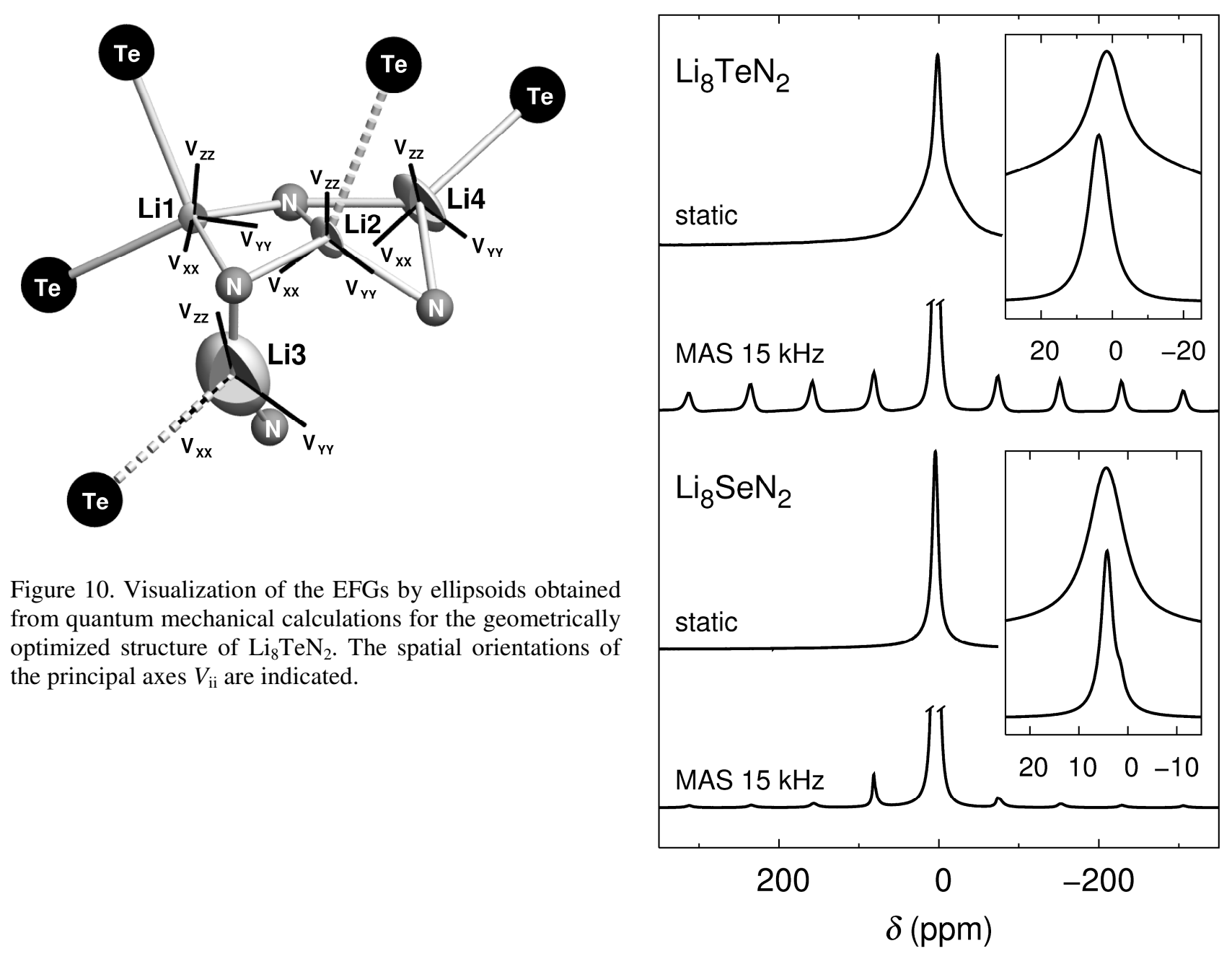

Figure 11. Static and MAS ${ }^{7} \mathrm{Li}$ NMR signals for $\mathrm{Li}_{8} \mathrm{SeN}_{2}$ and $\mathrm{Li}_{8} \mathrm{TeN}_{2}$. 


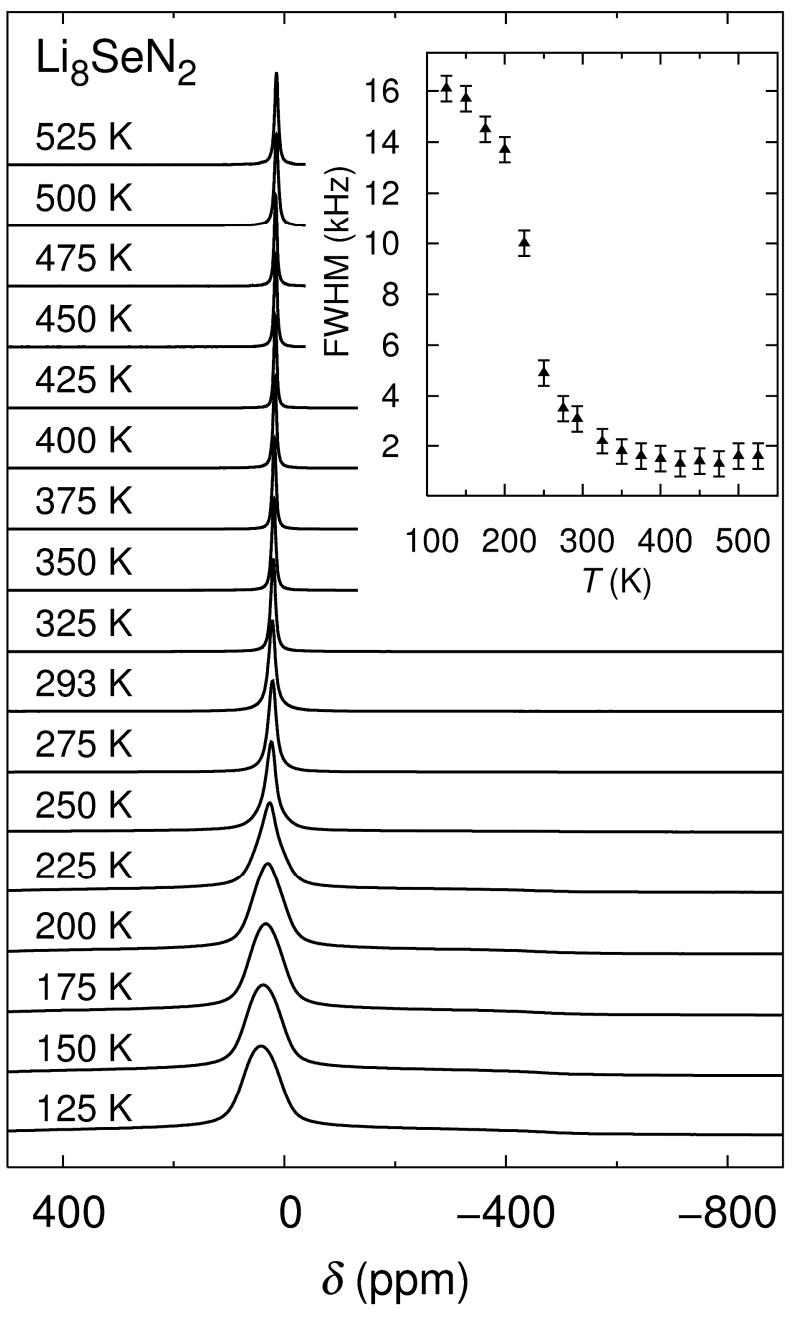

Figure 12. Temperature dependent ${ }^{7} \mathrm{Li}$ NMR measurements of $\mathrm{Li}_{8} \mathrm{SeN}_{2}$ (left) and $\mathrm{Li}_{8} \mathrm{TeN}_{2}$ (right) with an analysis of the full width at half maximum (FWHM) as a function of temperature (inset). Error bars of $\pm 0.5 \mathrm{kHz}$ for the FWHM are indicated.

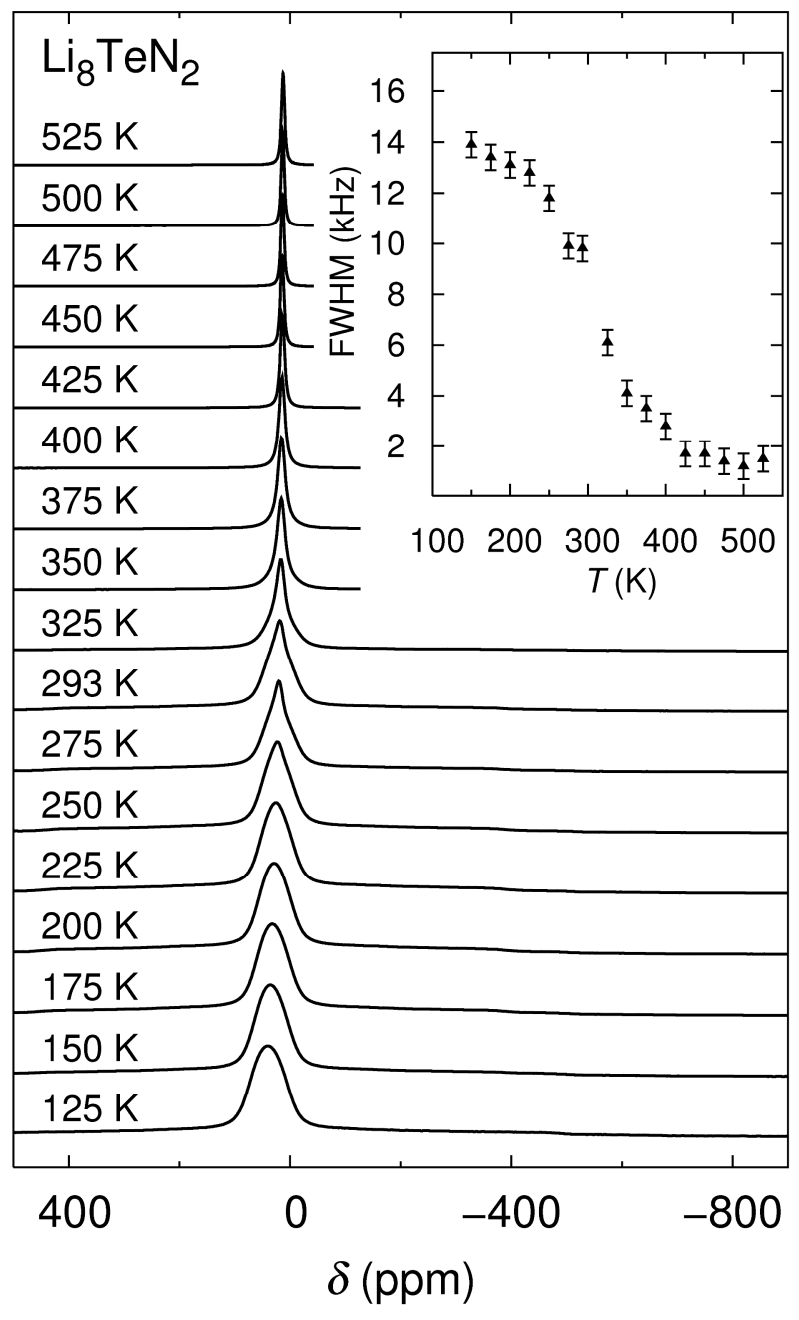




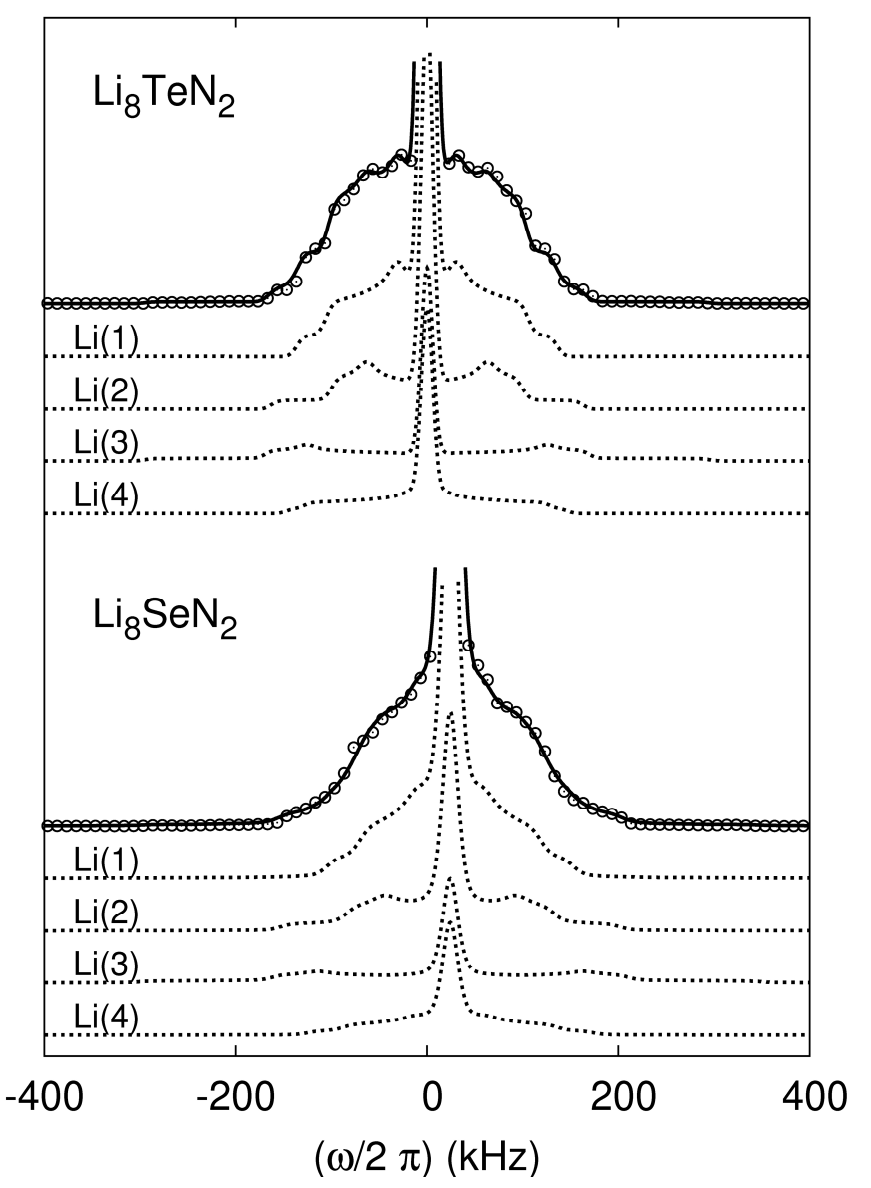

Figure 13. ${ }^{7} \mathrm{Li}$ frequency sweep NMR measurements at $T=$ $15 \mathrm{~K}$ for $\mathrm{Li}_{8} \mathrm{SeN}_{2}$ (bottom) and $\mathrm{Li}_{8} \mathrm{TeN}_{2}$ (top). Data points of the various experiments are indicated by open circles. The full line represents the result of the least-squares fit and the dashed lines the individual signal contributions. 
Table $1 . \mathrm{Li}_{8} \mathrm{SeN}_{2}$ : Crystal structure data from single crystal X-ray diffraction.

\begin{tabular}{ll}
\hline Formula & $\mathrm{Li}_{8} \mathrm{SeN}_{2}$ \\
Cryst. size, $\mathrm{mm}^{3}$ & $0.05 \times 0.05 \times 0.03$ \\
Crystal system & Tetragonal \\
Space group & $I 4_{1} m d($ No. 109) \\
$a, \AA$ & $7.060(2)$ \\
$c, \AA$ & $9.9689(7)$ \\
$V, \AA^{3}$ & $496.85(9)$ \\
$Z$ & 4 \\
$D_{\text {calcd }}, \mathrm{g} \mathrm{cm}^{-3}$ & 2.172 \\
$\mu\left(\mathrm{Mo} K_{\alpha}\right), \mathrm{mm}^{-1}$ & 7.38 \\
$T, \mathrm{~K}$ & 298 \\
$h k l$ range & $\pm 11, \pm 11, \pm 16$ \\
$2 \theta$ max, deg & 70.1 \\
Refl. measured & 3949 \\
Refl. unique & 606 \\
$R_{\text {int }}$ & 0.076 \\
Param. refined & 34 \\
BASF & $0.02(4)$ \\
$R(F) / w R\left(F^{2}\right)$ & $0.043 / 0.070$ \\
GooF $\left(F^{2}\right)$ & 1.19 \\
$\Delta \rho_{\text {fin }}$, e A ${ }^{-3}$ & 1.64 \\
\hline
\end{tabular}

Table 2. $\mathrm{Li}_{8} \mathrm{SeN}_{2}$ : Positional parameters and displacement parameters $U_{\mathrm{ij}}$ and $U_{\text {eq }}\left(\mathrm{in} \AA^{2}\right.$ ) from single crystal X-ray diffraction.

\begin{tabular}{lcccccccccccc}
\hline Atom & Site & $x$ & $y$ & $z$ & $U_{11}$ & $U_{22}$ & $U_{33}$ & $U_{12}$ & $U_{13}$ & $U_{23}$ \\
\hline $\mathrm{Se}$ & $4 a$ & 0 & 0 & $0.89813(9)$ & $0.0093(5)$ & $0.0193(5)$ & $0.0109(2)$ & 0 & 0 & 0 & $0.0132(1)$ \\
$\mathrm{N}$ & $8 b$ & $1 / 2$ & $0.2671(6)$ & $0.0003(3)$ & $0.011(1)$ & $0.007(2)$ & $0.006(2)$ & 0 & 0 & $0.003(2)$ & $0.0079(7)$ \\
$\mathrm{Li}(1)$ & $16 c$ & $0.7644(9)$ & $0.188(1)$ & $0.0773(6)$ & $0.021(3)$ & $0.024(3)$ & $0.018(3)$ & $0.002(2)$ & $-0.002(2)$ & $0.003(2)$ & $0.021(1)$ \\
$\mathrm{Li}(2)$ & $8 b$ & $1 / 2$ & $0.151(2)$ & $0.191(1)$ & $0.013(4)$ & $0.032(5)$ & $0.029(4)$ & 0 & 0 & $0.018(4)$ & $0.025(2)$ \\
$\mathrm{Li}(3)$ & $4 a$ & $1 / 2$ & 0 & $0.962(2)$ & $0.029(8)$ & $0.019(7)$ & $0.030(8)$ & 0 & 0 & 0 & $0.026(3)$ \\
$\mathrm{Li}(4)$ & $4 a$ & $1 / 2$ & 0 & $0.383(2)$ & $0.022(6)$ & $0.05(1)$ & $0.016(7)$ & 0 & 0 & 0 \\
\hline
\end{tabular}

Table 3. Selected data of Rietveld refinements: simultaneous X-ray and neutron diffraction refinements at $300 \mathrm{~K}$ and single neutron diffraction refinements at $3 \mathrm{~K}$. Number of refined structural parameters: 17 . Radiation: $\mathrm{Cu} K \alpha_{1}$ or $\lambda=1.5482 \AA$, respectively.

\begin{tabular}{|c|c|c|c|c|c|c|}
\hline Composition & X-ray & $\begin{array}{l}\mathrm{Li}_{8} \mathrm{SeN}_{2} \\
\text { neutron } \\
\mathrm{K}\end{array}$ & $\begin{array}{l}\text { neutron } \\
3 \mathrm{~K}\end{array}$ & X-ray & $\begin{array}{l}\mathrm{Li}_{8} \mathrm{TeN}_{2} \\
\text { neutron } \\
\mathrm{K}\end{array}$ & $\begin{array}{l}\text { neutron } \\
3 \mathrm{~K}\end{array}$ \\
\hline Unit cell parameter $a, \AA$ & \multicolumn{2}{|c|}{$7.048(1)$} & $7.024(1)$ & \multicolumn{2}{|c|}{$7.217(1)$} & $7.190(1)$ \\
\hline Unit cell parameter $c, \AA$ & \multicolumn{2}{|c|}{$9.995(1)$} & $9.953(1)$ & \multicolumn{2}{|c|}{$10.284(1)$} & $10.234(1)$ \\
\hline $2 \theta$-range, deg & $10.1-90.0$ & $22.3-125.0$ & $22.3-125.0$ & $10.1-90.0$ & $12.3-124.0$ & $12.3-124.0$ \\
\hline Step size, deg & 0.01 & 0.05 & 0.05 & 0.01 & 0.05 & 0.05 \\
\hline$\chi^{2}$ & \multicolumn{2}{|c|}{11.4} & 6.99 & \multicolumn{2}{|c|}{3.17} & 3.53 \\
\hline$R_{\text {profile }} R_{\text {Bragg }}$ & $0.107,0.098$ & $0.041,0.058$ & $0.023,0.038$ & $0.064,0.061$ & $0.036,0.057$ & $0.022,0.035$ \\
\hline
\end{tabular}


Table 4. $\mathrm{Li}_{8} E \mathrm{~N}_{2}$ : Positional parameters and isotropic displacement parameters $B_{\text {eq }}$ (in $\AA^{2}$ ). First line from simultaneous X-ray and neutron powder diffraction at $300 \mathrm{~K}$, second line in bold from neutron powder diffraction at $3 \mathrm{~K}$.

\begin{tabular}{|c|c|c|c|c|c|}
\hline Atom & Site & $x$ & $y$ & $z$ & $B_{\text {eq }}$ \\
\hline \multirow[t]{2}{*}{$\mathrm{Se}$} & $4 a$ & 0 & 0 & $0.8983(5)$ & $1.22(7)$ \\
\hline & & & & $0.8981(3)$ & $0.67(4)$ \\
\hline \multirow[t]{2}{*}{$\mathrm{N}$} & $8 b$ & $1 / 2$ & $0.2678(3)$ & 0 & $0.77(4)$ \\
\hline & & & $0.2681(2)$ & & $0.51(2)$ \\
\hline \multirow[t]{2}{*}{$\operatorname{Li}(1)$} & $16 c$ & $0.772(1)$ & $0.183(2)$ & $0.077(1)$ & $2.3(1)$ \\
\hline & & $0.775(1)$ & $0.182(1)$ & $0.077(1)$ & 1.7(1) \\
\hline \multirow[t]{2}{*}{$\operatorname{Li}(2)$} & $8 b$ & $1 / 2$ & $0.152(2)$ & $0.199(2)$ & $3.3(3)$ \\
\hline & & & $0.154(1)$ & $0.199(1)$ & $2.5(2)$ \\
\hline \multirow[t]{2}{*}{$\operatorname{Li}(3)$} & $4 a$ & $1 / 2$ & 0 & $0.949(3)$ & $2.9(5)$ \\
\hline & & & & $0.950(2)$ & $2.1(3)$ \\
\hline \multirow[t]{2}{*}{$\operatorname{Li}(4)$} & $4 a$ & $1 / 2$ & 0 & $0.398(3)$ & $3.2(6)$ \\
\hline & & & & $0.398(2)$ & $2.1(3)$ \\
\hline \multirow[t]{2}{*}{$\mathrm{Te}$} & $4 a$ & 0 & 0 & $0.8969(3)$ & $1.20(2)$ \\
\hline & & & & $0.8962(1)$ & $0.76(2)$ \\
\hline \multirow[t]{2}{*}{$\mathrm{N}$} & $8 b$ & $1 / 2$ & $0.2686(2)$ & 0 & $1.20(2)$ \\
\hline & & & $0.2693(1)$ & & $0.84(1)$ \\
\hline \multirow[t]{2}{*}{$\operatorname{Li}(1)$} & $16 c$ & $0.7541(8)$ & $0.1871(9)$ & $0.0787(6)$ & $1.7(1)$ \\
\hline & & $0.7583(4)$ & $0.1866(4)$ & $0.0778(3)$ & $1.55(5)$ \\
\hline \multirow[t]{2}{*}{$\operatorname{Li}(2)$} & $8 b$ & $1 / 2$ & $0.157(1)$ & $0.193(1)$ & $2.5(1)$ \\
\hline & & & $0.1549(6)$ & $0.1939(4)$ & $1.58(7)$ \\
\hline \multirow[t]{2}{*}{$\operatorname{Li}(3)$} & $4 a$ & $1 / 2$ & 0 & $0.957(1)$ & $2.9(3)$ \\
\hline & & & & $0.9560(7)$ & $2.4(1)$ \\
\hline \multirow[t]{2}{*}{$\operatorname{Li}(4)$} & $4 a$ & $1 / 2$ & 0 & $0.373(1)$ & $3.7(4)$ \\
\hline & & & & $0.3805(7)$ & $2.5(1)$ \\
\hline
\end{tabular}

Table 5. $\mathrm{Li}_{8} E \mathrm{~N}_{2}$ : Selected interatomic distances (in $\AA$ ) from simultaneous X-ray and neutron powder diffraction at $300 \mathrm{~K}$. First line: $E=\mathrm{Se}$, second line in bold: $E=\mathrm{Te}$.

\begin{tabular}{|c|c|c|c|c|c|}
\hline $\mathrm{N}-\mathrm{Li}(1)$ & $\begin{array}{l}2.15(1) \\
\mathbf{2 . 0 9 0}(6)\end{array}$ & $2 \times$ & $E-\mathrm{N}$ & $\begin{array}{l}\geq 3.990(4) \\
\geq 4.231(1)\end{array}$ & \\
\hline N-Li(1) & $2.17(1)$ & $2 \times$ & & & \\
\hline & $2.25(6)$ & & $E-\operatorname{Li}(1)$ & $2.73(1)$ & $4 \times$ \\
\hline $\mathrm{N}-\mathrm{Li}(2)$ & $2.02(1)$ & $2 \times$ & & $2.910(6)$ & \\
\hline & $2.098(8)$ & & $E-\operatorname{Li}(1)$ & $2.84(1)$ & $4 \times$ \\
\hline $\mathrm{N}-\mathrm{Li}(2)$ & $2.15(2)$ & $1 \times$ & & $2.956(6)$ & \\
\hline & $2.15(1)$ & & $E-\mathrm{Li}(4)$ & $2.50(4)$ & $1 \times$ \\
\hline $\mathrm{N}-\mathrm{Li}(3)$ & $\begin{array}{l}1.955(8) \\
\mathbf{1 . 9 9 0 ( 3 )}\end{array}$ & $1 \times$ & & 2.81(1) & \\
\hline N-Li(4) & $\begin{array}{l}2.20(2) \\
\mathbf{2 . 1 0}(\mathbf{1})\end{array}$ & $1 \times$ & & & \\
\hline
\end{tabular}


Table 6. ${ }^{7} \mathrm{Li}$ NMR parameters for $\mathrm{Li}_{8} \mathrm{SeN}_{2}$ and $\mathrm{Li}_{8} \mathrm{TeN}_{2}$ obtained by quantum mechanical calculations and least-square fits of the low temperature frequency sweep NMR signals (experiment). The isotropic shift $\delta_{\text {iso }}$, anisotropy $\delta_{\text {aniso }}$ and asymmetry parameter $\eta_{\delta}$ of the chemical shielding as well as the quadrupolar coupling constant $C_{Q}$ and the asymmetry parameter of the quadrupolar coupling $\eta_{Q}$ for the Li sites are given. The sign of the quadrupolar coupling constant can not be determined by NMR experiments. The average referenced isotropic shift of the Li atoms is determined by the maxima of the MAS signals recorded at ambient temperature using a rotation frequency of $15 \mathrm{kHz}$. The calculated isotropic shifts are not referenced. Only the differences of the individual calculated values are of interest for that reason.

\begin{tabular}{|c|c|c|c|c|c|c|c|c|c|c|}
\hline & \multicolumn{5}{|c|}{$\mathrm{Li}_{8} \mathrm{SeN}_{2}$} & \multicolumn{5}{|c|}{$\mathrm{Li}_{8} \mathrm{TeN}_{2}$} \\
\hline & $\delta_{\mathrm{so}} / \mathrm{ppm}$ & $\delta_{\text {aniso }} / \mathrm{ppm}$ & $\eta_{\delta}$ & $C_{Q} / \mathrm{MHz}$ & $\eta_{Q}$ & $\delta_{\text {iso }} / \mathrm{ppm}$ & $\delta_{\text {aniso }} / \mathrm{ppm}$ & $\eta_{\delta}$ & $C_{Q} / \mathrm{MHz}$ & $\eta_{Q}$ \\
\hline \multicolumn{11}{|c|}{ Based on structure model obtained by neutron diffraction experiments at $T=3 \mathrm{~K}$} \\
\hline $\operatorname{Li}(1)$ & -84.73 & -3.96 & 0.44 & 0.24 & 0.92 & -85.16 & -4.61 & 0.39 & 0.30 & 0.54 \\
\hline $\operatorname{Li}(2)$ & -83.40 & 3.78 & 0.17 & -0.36 & 0.12 & -83.67 & 3.97 & 0.27 & -0.31 & 0.12 \\
\hline $\operatorname{Li}(3)$ & -82.55 & -17.60 & 0.06 & 0.68 & 0.26 & -83.93 & -15.81 & 0.05 & 0.65 & 0.24 \\
\hline $\operatorname{Li}(4)$ & -85.16 & 5.15 & 0.52 & -0.31 & 0.13 & -85.29 & 5.40 & 0.24 & -0.33 & 0.67 \\
\hline \multicolumn{11}{|c|}{ Based on geometrical optimized structure model } \\
\hline $\operatorname{Li}(1)$ & -84.85 & -4.54 & 0.29 & 0.27 & 0.67 & -85.14 & -4.95 & 0.35 & 0.32 & 0.46 \\
\hline $\operatorname{Li}(2)$ & -83.09 & 3.82 & 0.61 & -0.37 & 0.20 & -83.58 & 4.02 & 0.47 & -0.31 & 0.23 \\
\hline $\operatorname{Li}(3)$ & -83.06 & -18.30 & 0.03 & 0.73 & 0.15 & -83.96 & -15.99 & 0.03 & 0.66 & 0.22 \\
\hline $\mathrm{Li}(4)$ & -85.04 & 5.37 & 0.40 & -0.34 & 0.56 & -85.33 & 5.51 & 0.48 & -0.34 & 0.77 \\
\hline \multicolumn{11}{|c|}{ Experiment } \\
\hline $\mathrm{Li}(1)$ & & & & $0.26(2)$ & $0.5(1)$ & & & & $0.27(2)$ & $0.6(1)$ \\
\hline $\operatorname{Li}(2)$ & 43 & - & - & $0.35(2)$ & $0.2(1)$ & 40 & - & - & $0.33(2)$ & $0.2(1)$ \\
\hline $\operatorname{Li}(3)$ & & & & $0.65(2)$ & $0.2(1)$ & & & - & $0.59(2)$ & $0.2(1)$ \\
\hline $\mathrm{Li}(4)$ & & & & $0.30(2)$ & $0.5(1)$ & & & & $0.29(2)$ & $0.7(1)$ \\
\hline
\end{tabular}




\section{Experimental Section}

\section{Preparation}

All manipulations were carried out under dry argon in a glovebox $\left(p\left(\mathrm{O}_{2}, \mathrm{H}_{2} \mathrm{O}\right)<0.1 \mathrm{ppm}\right) . \mathrm{Li}_{3} \mathrm{~N}$ was prepared from elemental lithium (rods, Alfa, 99.9\%) and nitrogen (Messer-Griesheim, 99.999\%, additionally purified by passing over molsieve, Roth $3 \AA$, and BTS catalyst, Merck) of ambient pressure at $670 \mathrm{~K}$. The lithium chalcogenides $\mathrm{Li}_{2} E$ ( $E=\mathrm{Se}$, Te) were obtained from the elements in sealed tantalum ampoules at $575 \mathrm{~K}$ and $775 \mathrm{~K}$, respectively. For synthesis of $\mathrm{Li}_{8} \mathrm{SeN}_{2}$ and $\mathrm{Li}_{8} \mathrm{TeN}_{2}$ appropriate molar ratios of $\mathrm{Li}_{3} \mathrm{~N}$ und $\mathrm{Li}_{2} E$ were reacted at $1023 \mathrm{~K}$ in sealed tantalum ampoules. The products were microcrystalline orange powders with a slightly darker color for the tellurium compound. Both ternary nitrides are sensitive against moist air.

In synthesis experiments with excess $\mathrm{Li}$ small single crystals of $\mathrm{Li}_{8} \mathrm{SeN}_{2}$ were obtained using the above mentioned conditions.

\section{Thermal analysis}

Difference scanning calorimetry was performed on a DSC 204 Phoenix (Netzsch) in Ar-filled sealed aluminum crucibles. DTA/TG measurements (STA 409, Netzsch, Nb crucibles, thermocouple type S) were performed under nitrogen and argon to analyze the formation of the ternary compounds, to find the optimum reaction conditions, and to examine the decomposition behaviour. Temperature calibration was carried out with five melting points of pure metals.

\section{$X$-ray diffraction}

In-house X-ray powder diffraction pattern were taken in transmission (STADIP, STOE) with $\mathrm{Cu} K \alpha_{1}$ radiation.

$\mathrm{X}$-ray diffraction on a single crystal $\mathrm{Li}_{8} \mathrm{SeN}_{2}$ (sealed in a glass capillary) was performed on a MSC-Rigaku R-Axis Rapid diffractometer applying $\mathrm{MoK} \alpha$-radiation. An absorption correction based on symmetry-equivalent reflections was applied [41]. In situ crystal structure investigations between room temperature and $1098 \mathrm{~K}$ were carried out with high-resolution powder diffraction applying synchrotron radiation (beamline B2, HASYLAB at DESY). The diffraction experiments were performed in Debye-Scherrer capillary geometry with the samples sealed in quartz capillaries using an on-site readable image plate detector OBI [42]. The wavelength of $0.65131 \AA$ was calibrated using the reflection positions of $\mathrm{LaB}_{6}$ (NIST SRM 660a) reference material. The typical full-width at half-maximum (FWHM) of reflections obtained in this geometry was $0.06-0.08^{\circ}$. A STOE furnace was used for in situ HT diffraction experiments. For $\mathrm{Li}_{8} \mathrm{TeN}_{2}$ patterns were taken from room temperature to $548 \mathrm{~K}$ in steps of $25 \mathrm{~K}$, and from $598 \mathrm{~K}$ to $1098 \mathrm{~K}$ in steps of $100 \mathrm{~K}$. All patterns were recorded for a duration of $9 \mathrm{~min}$. Due to apparent chemical reactions of $\mathrm{Li}_{8} \mathrm{SeN}_{2}$ the measurements were restricted to a maximum of $900 \mathrm{~K}$ with recording times of $15 \mathrm{~min}$ per pattern.

\section{Neutron powder diffraction}

The samples were placed in argon-filled cylindrical vanadium containers (diameter $8 \mathrm{~mm}$; length $51 \mathrm{~mm}$; wall thickness $0.15 \mathrm{~mm}$ ) and sealed with indium gaskets. Patterns were collected at 3,50,100,150,200, 250 and $300 \mathrm{~K}$ at the SPODI diffractometer of FRM II with the wavelength of $1.5482 \AA$.

\section{Structure refinements}

For all Rietveld refinements the program package FULLPROF [43] was used. For all refinements against powder data the fractional coordinate $z$ of $\mathrm{N}$ (highest contribution to neutron diffraction due to high diffraction length) was fixed to zero. The crystal structure of $\mathrm{Li}_{8} \mathrm{SeN}_{2}$ based on data from single crystal diffraction intensity collection was refined with the program system SHELXL-97-2 [44].
Chemical analyses for $\mathrm{N}$ and $\mathrm{O}$ were carried out via hot-gasextraction (LECO $436 \mathrm{DR}$ ). Li, Se and Te were quantified applying the inductively coupled plasma-optical emission spectrometry (ICP-OES, Varian, VISTA RL) method.

\section{NMR spectroscopy and quantum mechanical calculations}

${ }^{7} \mathrm{Li}$ NMR spectroscopic investigations were performed by using a Bruker AVANCE spectrometer with a magnetic field of $B_{0}=11.74$ $\mathrm{T}$. The corresponding resonance frequency of the ${ }^{7} \mathrm{Li}$ isotope is 194.373 MHz. The NMR signals are referenced to a saturated solution of $\mathrm{LiCl}$ in $\mathrm{D}_{2} \mathrm{O}$.

Magic angle spinning (MAS) NMR experiments were carried out for different rotation frequencies at ambient temperature on powder samples of $\mathrm{Li}_{8} \mathrm{SeN}_{2}$ and $\mathrm{Li}_{8} \mathrm{TeN}_{2}$ filled into $\mathrm{ZrO}_{2}$ rotors $(4.0 \mathrm{~mm}$ diameter) using a Bruker double resonance MAS probe. Full recovery of the magnetization at ambient temperature was achieved within $1.0 \mathrm{~s}$. Single pulse experiments with hard pulses of $3.5 \mu \mathrm{s}$ duration were applied for the Se compound. An echo pulse sequence with pulses of equal duration of $2.5 \mu \mathrm{s}$ was used for $\mathrm{Li}_{8} \mathrm{TeN}_{2}$. The interpulse delay was synchronized with the rotation frequency.

Wide line variable-temperature ${ }^{7} \mathrm{Li}$ NMR signals were recorded for randomly oriented crystallites of $\mathrm{Li}_{8} \mathrm{SeN}_{2}$ and $\mathrm{Li}_{8} \mathrm{TeN}_{2}$ enclosed in a sealed glass ampoule over a temperature range of $125 \mathrm{~K}$ to $525 \mathrm{~K}$. Depending on the spectral width at different temperatures either single pulse experiments with hard pulses of $3.0 \mu$ s duration or an echo sequence with pulses of equal duration of $1.5 \mu$ s were applied. The interpulse distance of the echo sequence was optimized to $100 \mu$ s to avoid distortions of the NMR signal line shape.

Frequency sweep ${ }^{7} \mathrm{Li}$ NMR experiments at $15 \mathrm{~K}$ were performed on the powder samples of $\mathrm{Li}_{8} \mathrm{SeN}_{2}$ and $\mathrm{Li}_{8} \mathrm{TeN}_{2}$ mounted on a low$Q$ probe with automatic tuning and matching built by NMRService (Erfurt, Germany). The temperature was adjusted in a helium cryostat system. A series of selective excitation experiments was applied using low-power pulses of $100 \mu \mathrm{s}$.

NMR signals were simulated using the SIMPSON [45] program package using $\delta_{\text {iso }}=1 / 3\left(\delta_{\mathrm{XX}}+\delta_{\mathrm{YY}}+\delta_{\mathrm{ZZ}}\right), \delta_{\text {aniso }}=\delta_{\mathrm{ZZ}}-\delta_{\text {iso }}$ and $\eta_{\delta}$ $=\left(\delta_{\mathrm{XX}}-\delta_{\mathrm{YY}}\right) / \delta_{\text {aniso }}$ for the isotropic, the anisotropic, and the asymmetry parameter of the chemical shielding, respectively. The order of the principal axes of the shielding tensor is defined by $\mid \delta_{\mathrm{ZZ}}$ $-\delta_{\text {iso }}|\geq| \delta_{\mathrm{Xx}}-\delta_{\text {iso }}|\geq| \delta_{\mathrm{YY}}-\delta_{\text {iso }} \mid$ resulting in $0 \leq \eta_{\delta} \leq 1$. The quadrupole coupling constant is defined as $C_{Q}=\mathrm{e} Q V_{\mathrm{ZZ}} / \eta$ with the nuclear quadrupole moment $Q\left({ }^{7} \mathrm{Li}\right)=-4.01 \mathrm{fm}^{2}[46]$ and the main principal component of the electric field gradient $V_{\mathrm{ZZ}}$. The asymmetry parameter of the quadrupole coupling is defined as $\eta_{Q}$ $=\left(V_{\mathrm{XX}}-V_{\mathrm{YY}}\right) / V_{\mathrm{ZZ}}$ with $\left|V_{\mathrm{ZZ}}\right| \geq\left|V_{\mathrm{XX}}\right| \geq\left|V_{\mathrm{YY}}\right|$ and $0 \leq \eta_{Q} \leq 1$.

Quadrupole coupling and chemical shift parameters were calculated using the NMR-CASTEP [33] code, within periodic boundary conditions and the pseudopotential approximation using the GIPAW [47] and PAW [34, 48] methods. On-the-fly generated ultrasoft pseudopotentials were used for the calculations. The calculations were performed with a cut-off energy of $450 \mathrm{eV}$ and with $4 \times 4 \times 5 k$ points using GGA (PBE [49]). Geometry optimizations were also performed using the code. The model of the crystal structure obtained at $3 \mathrm{~K}$ using neuton powder diffraction was used as basis for the geometry optimization.

Supporting Information Unit cell parameters at different temperatures are gathered in Tables S1 - S4. Further details of the single crystal structure investigation may be obtained from Fachinformationszentrum Karlsruhe, 76344 EggensteinLeopoldshafen, Germany (fax: +49-7247-808-666; e-mail: crysdata@fiz-karlsruhe.de, http://www.fizinformationsdienste.de/en/DB/icsd/depot_anforderung.html) on quoting the deposition number CSD-421252.

\section{Acknowledgments}

We would like to thank Anja Völzke for performing the chemical analyses, Susann Scharsach for DSC measurements and Yurii Prots for single crystal X-ray diffraction intensity data collection. 
[1] H. Sattlegger, H. Hahn, Z. Anorg. Allg. Chem. 1970, 379, 293-299.

[2] H. Sattlegger, H. Hahn, Naturwissenschaften 1964, 51, 534535 .

[3] P. Hartwig, W. Weppner, W. Wichelhaus, Mater. Res. Bull. 1979, 14, 493-498.

[4] P. Hartwig, W. Weppner, W. Wichelhaus, A. Rabenau, Angew. Chem. Int. Ed. Engl. 1980, 19, 74-75.

[5] K. Kitahama, Y. Furukawa, S. Kawai, O. Nakamura, Solid State Ionics 1981, 3/4, 335-339.

[6] Y. Jia, J. Yang, Solid State Ionics 1997, 96, 113-117.

[7] R. Marx, Z. Naturforsch. 1995, 50b, 1061-1066.

[8] R. Marx, J. Solid State Chem. 1997, 128, 241-246.

[9] R. Marx, H. M. Mayer, Z. Naturforsch. 1995, 50b, $1353-$ 1358.

[10] R. Marx, H. M. Mayer, J. Solid State Chem. 1997, 130, 9096.

[11] R. Marx, R. M. Ibberson, J. Alloys Compd. 1997, 261, 123131.

[12] R. Marx, H. M. Mayer, Z. Naturforsch. 1996, 51b, 525-530.

[13] R. Marx, J. Alloys Compd. 1997, 256, 196-206.

[14] R. Marx, Z. Anorg. Allg. Chem. 1997, 623, 1912-1916.

[15] R. Marx, Eur. J. Solid State Inorg. Chem. 1998, 35, 197-209.

[16] A. Rabenau, H. Schulz, J. Less-Common Met. 1976, 50, 155159.

[17] R. Marx, Habilitation Thesis, Freie Universität Berlin, 2002.

[18] R. Marx, F. Lissner, T. Schleid, Z. Anorg. Allg. Chem. 2006, 632, 2151

[19] T. B. Massalski (Ed.): Binary Alloy Phase Diagrams. $2^{\text {nd }}$ Ed., ASM International, Materials Park, Ohio 1990.

[20] International Tables for Crystallography, Volume C, $5^{\text {th }}$ Edition, Ed. T. Hahn, Kluwer Academic Publishers, 2002.

[21] H. U. Beister, S. Haag, R. Kniep, K. Strossner, K. Syassen, Angew. Chem. Int. Ed. Engl. 1988, 27, 1101-1103.

[22] E. Zintl, A. Harder, B. Dauth, Z. Electrochem. Angew. Phys. Chem. 1934, 40, 588-593.

[23] H. Bärnighausen, MATCH, Commun. Math. Chem. 1980, 9, 139-173.

[24] V. M. Goldschmidt, Z. Kristallogr. Mineral. 1909, 45, 548554; C. Palache, H. Berman, C. Fondel, Dana's system of Mineralogy, $7^{\text {th }}$ Ed. 1944, $356 f f$.

[25] T. Nilges, A. Pfitzner, Z. Kristallogr. 2005, 220, 281-294.

[26] H.-J. Deiseroth, S.-T. Kong, H. Eckert, J. Vannahme, C. Reiner, T. Zaiß, M. Schlosser, Angew. Chem. Int. Ed. 2008, $47,755-758$.

[27] H. Kohlmann, F. Fauth, P. Fischer, A. V. Skripov, V. N. Kozhanov, K. Yvon, J. Alloys Comp. 2001, 327, L4-L9 and references given therein.

[28] F. Gingl, K. Yvon, T. Vogt, A. Hewat, J. Alloys Comp. 1997, 253, 313-317.

[29] H. Kohlmann, F. Werner, K. Yvon, G. Hilscher, M. Reissner, G. J. Cuello, Chem. Eur. J. 2007, 13, 4178-4186.

[30] P. Blaha, K. Schwarz, P. Herzig, Phys. Rev. Lett. 1985, $54(11), 1192-1195$

[31] F. Haarmann, K. Koch, D. Grüner, W. Schnelle, O. Pecher, R. Cardoso-Gil, H. Borrmann, H. Rosner, Yu. Grin, Chem. Eur. J. 2009, 15, 1673-1684.

[32] S. E. Ashbrook, L. Le Pollès, R. Gautier, C. J. Pickard, R. I. Walton, Phys. Chem. Chem. Phys. 2006, 8, 3423-3431.
[33] S. J. Clark, M. D. Segall, C. J. Pickard, P. J. Hasnip, M. J. Probert, K. Refson, M. C. Payne, Z. Kristallogr. 2005, 220, 567-570.

[34] M. Profeta, F. Mauri, C. J. Pickard, J. Am. Chem. Soc. 2003, 125, 541-548.

[35] J. R. Yates, C. J. Pickard, F. Mauri, Phys Rev. B 2007, 76, 024401 .

[36] D. Brinkmann, W. Freudenreich, J. Ross, Solid State Commun. 1978, 28, 233-237.

[37] S.-T. Kong, H. J. Deiseroth, C. Reiner, Ö. Gün, E. Neumann, C. Ritter, D. Zahn, Chem. Eur. J. 2009, in press.

[38] O. Pecher, S.-T. Kong, C. Reiner, H. J. Deiseroth, F. Haarmann, D. Zahn, Chem. Eur. J. 2009, submitted.

[39] D. Trots, A. Senyshyn, D. A. Mikhailova, T. Vad, H. Fueß, J. Phys.: Condens. Matter 20 (2008) 455204.

[40] D. A. Keen, J. Phys.: Condens. Matter 2002, 14, R819-R857.

[41] R. Jacobson, Program REQAB, unpublished.

[42] M. Knapp, V. Joco, C. Baehtz, H. H. Brecht, A. Berghaeuser, H. Ehrenberg, H. von Seggern, H. Fueß, Nuclear Instruments and Methods in Physics Research A 2004, 521, 565-570.

[43] T. Roisnel, J. Rodriguez-Carvajal, WinPLOTR, Version May 2000, Materials Science Forum, Proceedings of the $7^{\text {th }}$ European Powder Diffraction Conference 2000, Barcelona, Spain, 188. J. Rodriguez-Carjaval, FULLPROF.2K, Version 1.6; 2000, Laboratoire Léon Brillouin: 2000, in: Abstract of Satellite Meeting on Powder Diffraction, Congress of the International Union of Crystallography, Toulouse, France, $1990,127$.

[44] G. M. Sheldrick, SHELXL-97-2, Program for the Refinement of Crystal Structures, Universität Göttingen, Göttingen, Germany, 1997.

[45] M. Bak, J. T. Rasmussen, N. Ch. Nielsen, J. Magn. Reson. 2000, 147, 296-330.

[46] R. K. Harris, E. D. Becker, J. Magn. Reson. 2002, 156, 323326.

[47] C. J. Pickard, F. Mauri, Phys. Rev. B 2001, 63, 245101.

[48] H. M. Petrilli, P. E. Blöchl, P. Blaha, K. Schwarz, Phys. Rev. $B$ 1998, 57, 14690-14697.

[49] J. P. Perdew, K. Burke, M. Ernzerhof, Phys. Rev. Lett. 1996, $77,3865-3868$

Received: ((will be filled in by the editorial staff)) Published online: ((will be filled in by the editorial staff)) 
Page 19 of 36

ZAAC

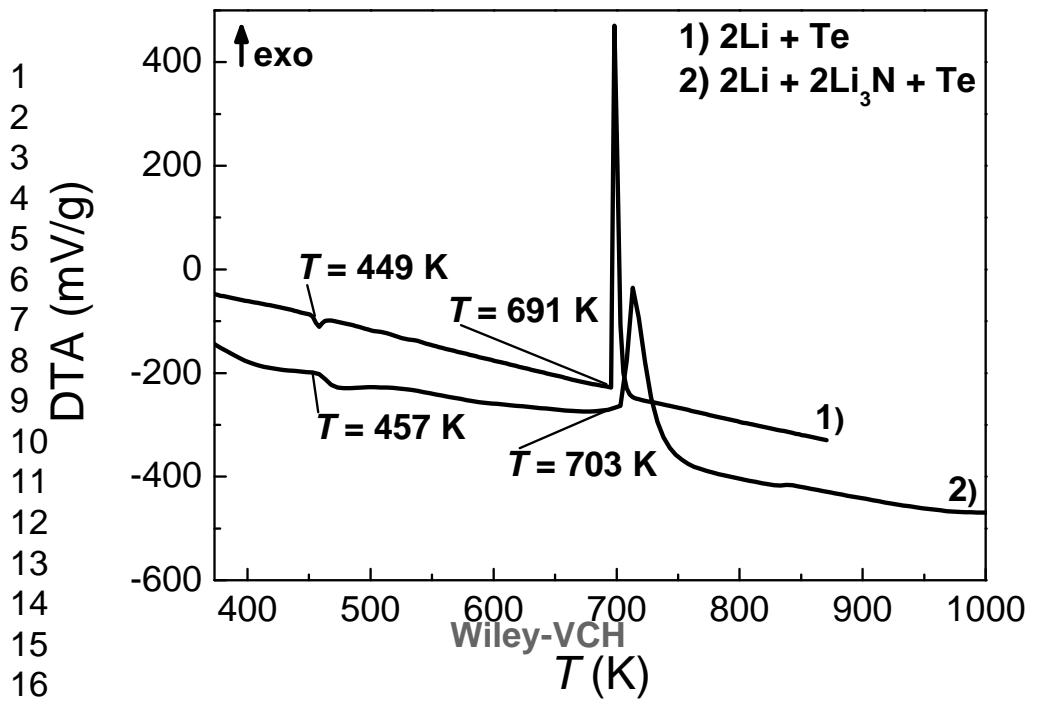

17 
ZAAC

Page 20 of 36

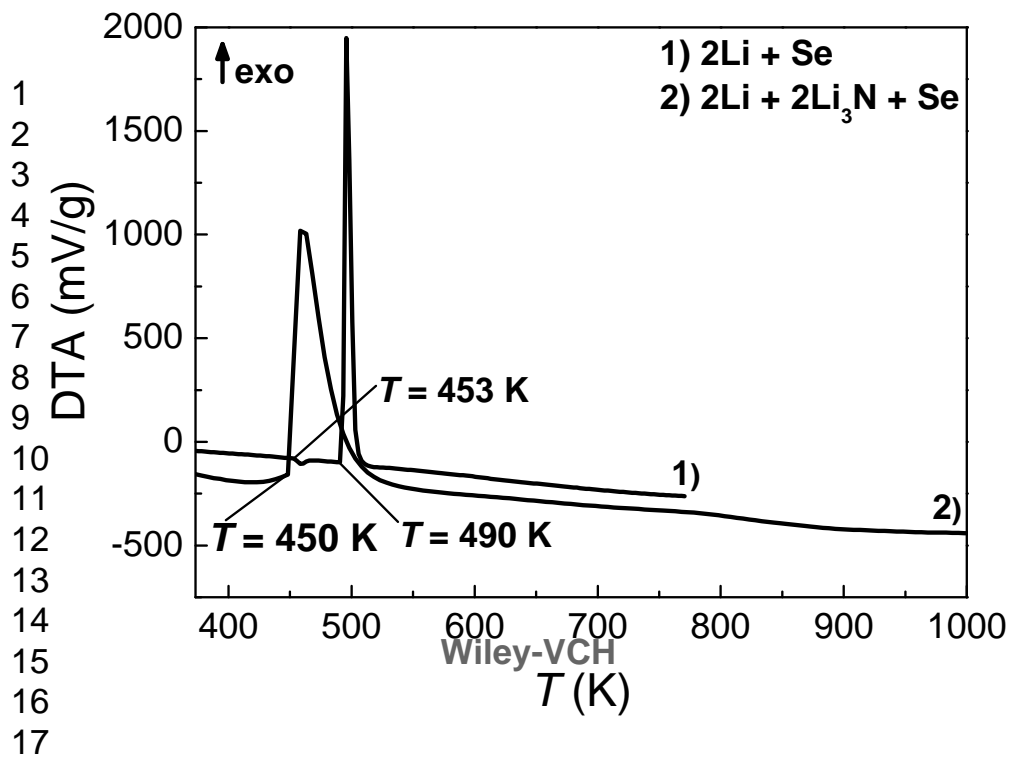


Page 21 of 36

ZAAC

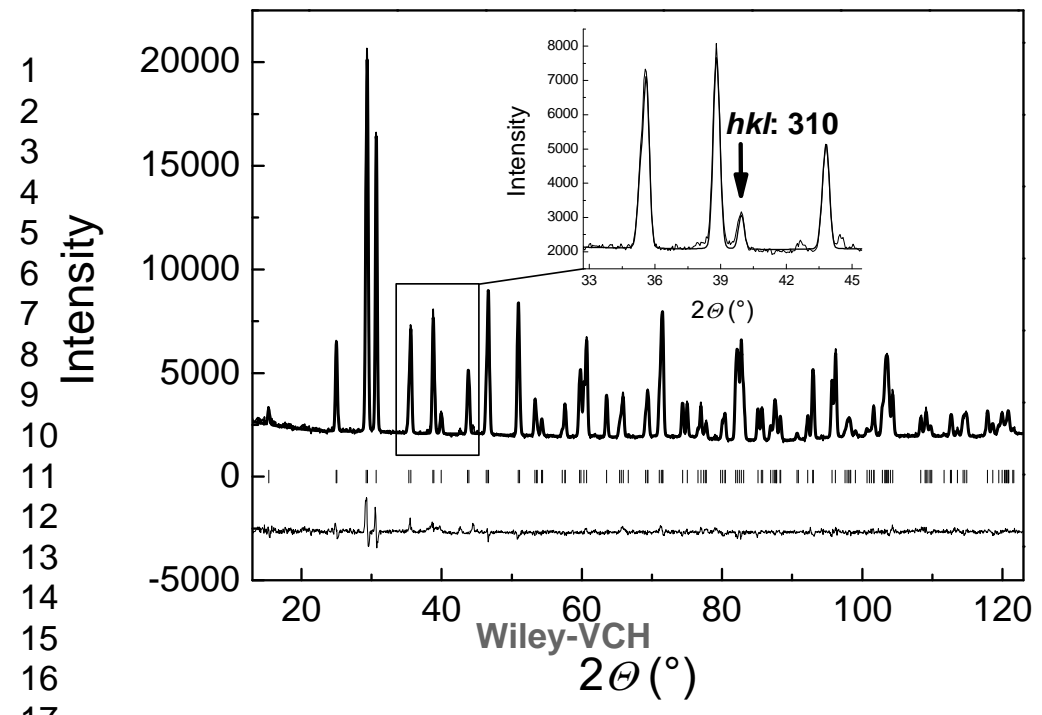

17

10 
ZAAC

Page 22 of 36

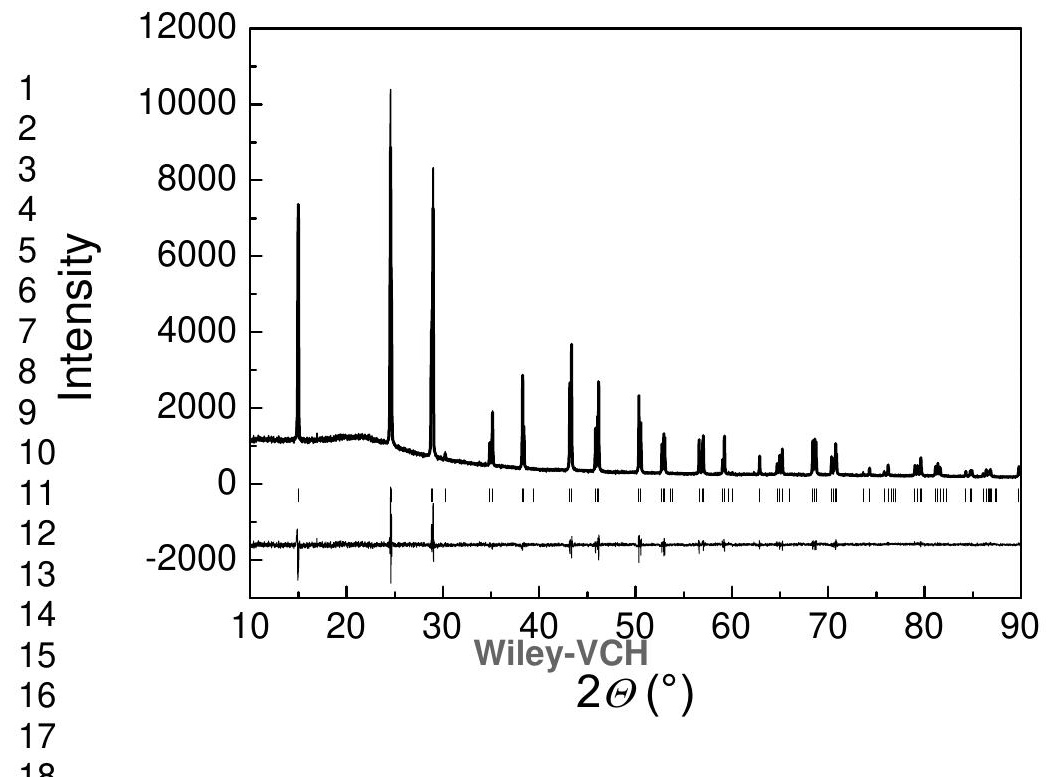




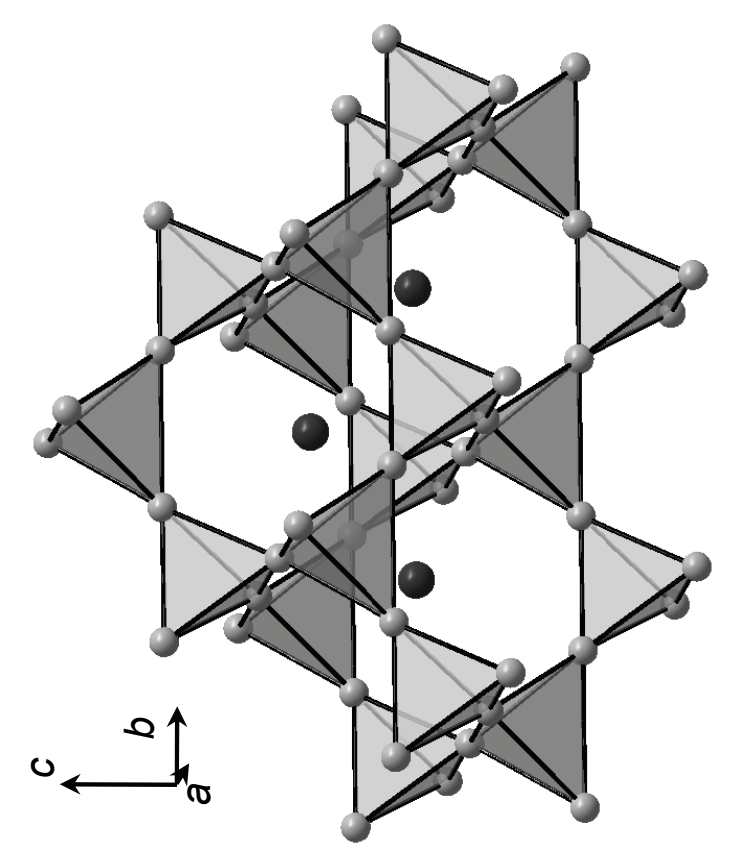




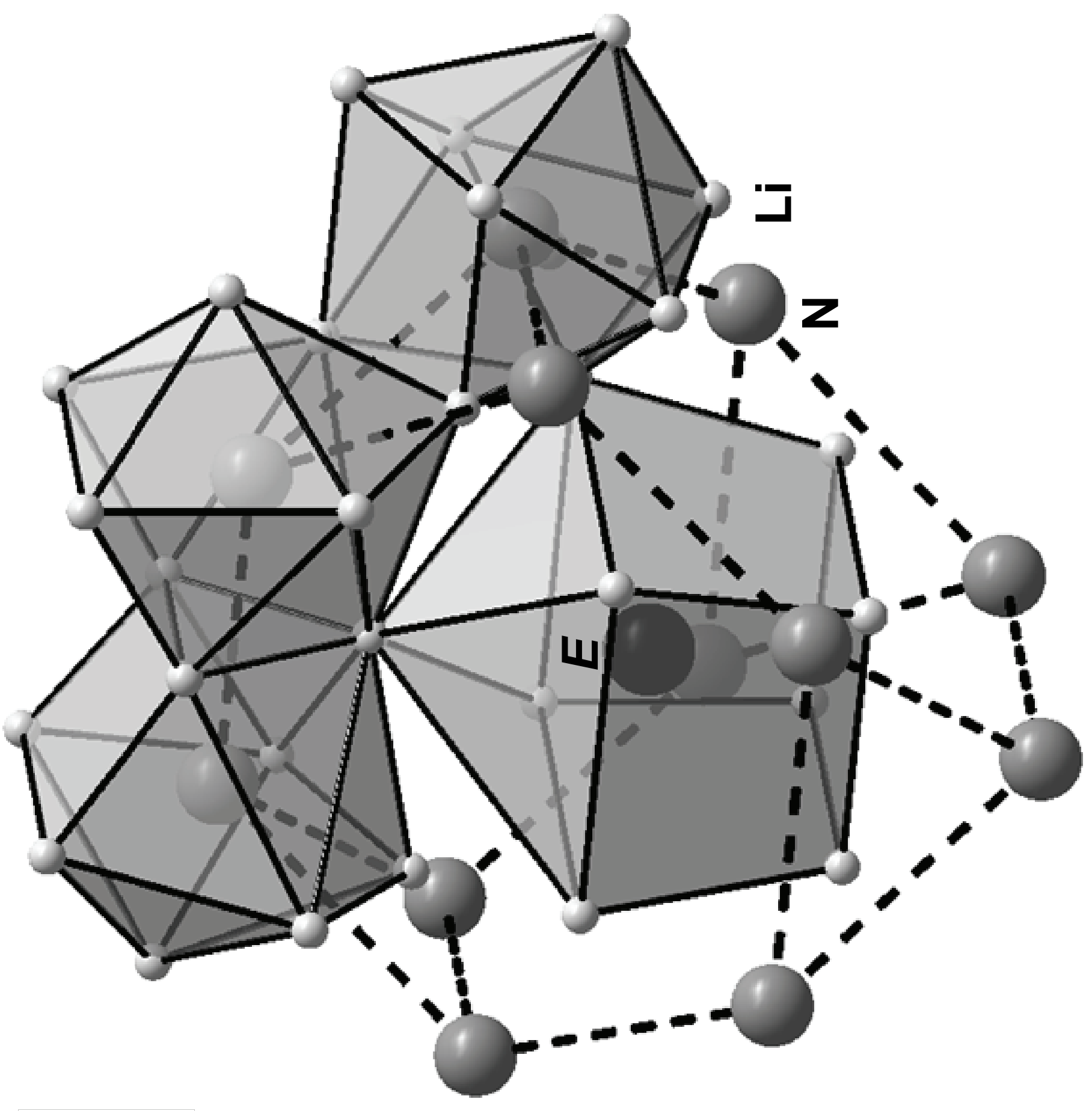




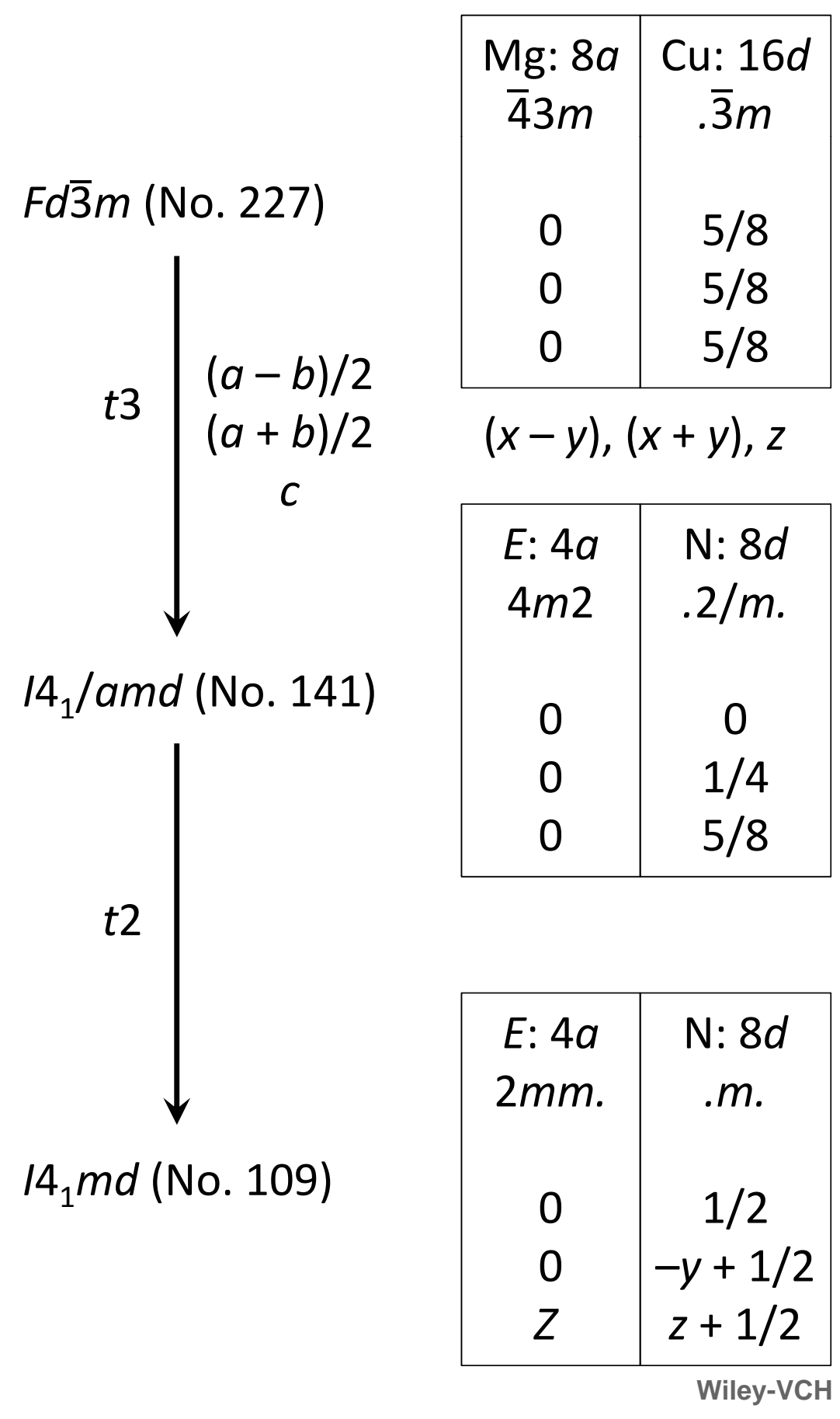


Page 27 of 36

ZAAC

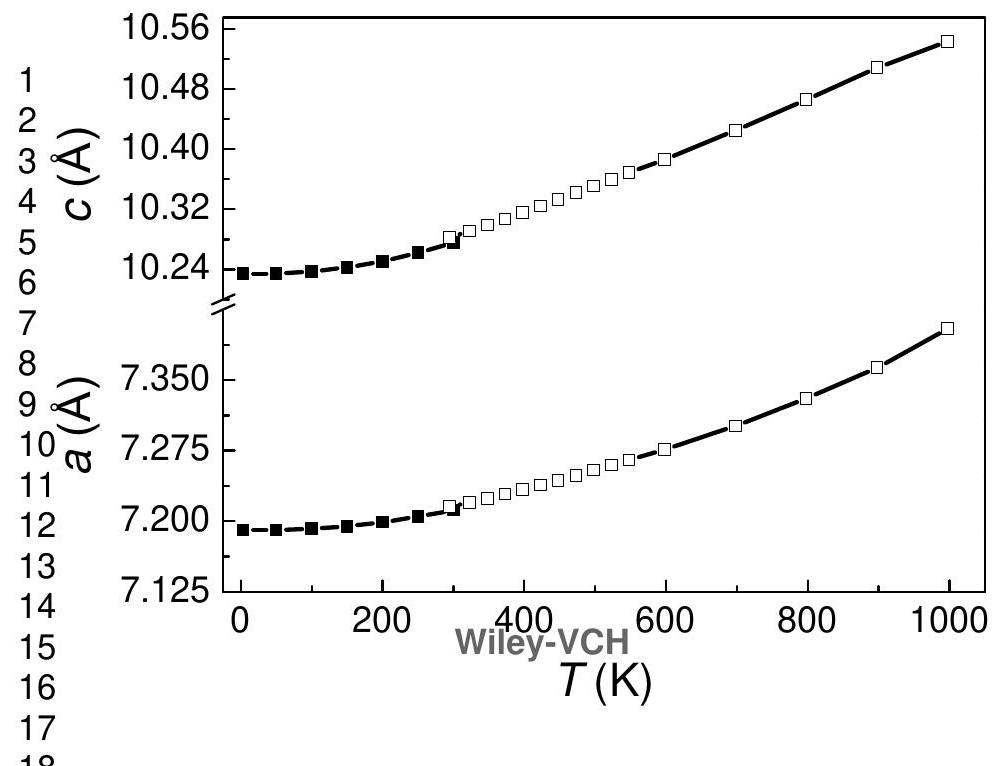


ZAAC

Page 28 of 36

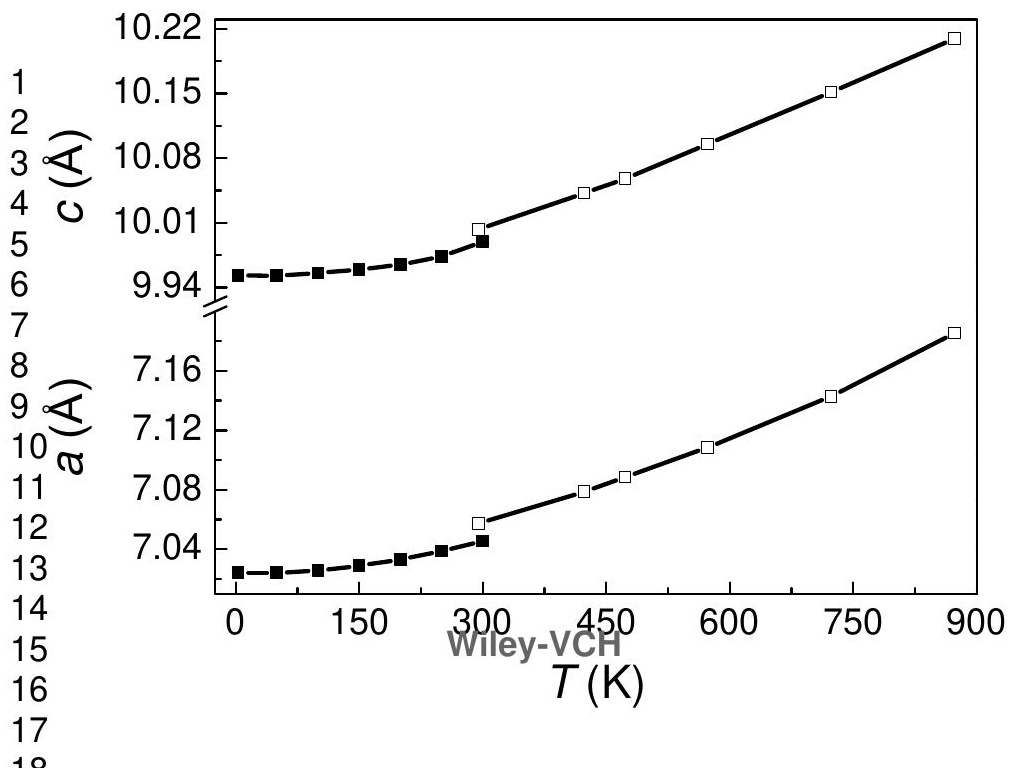


Page 29 of 36

ZAAC

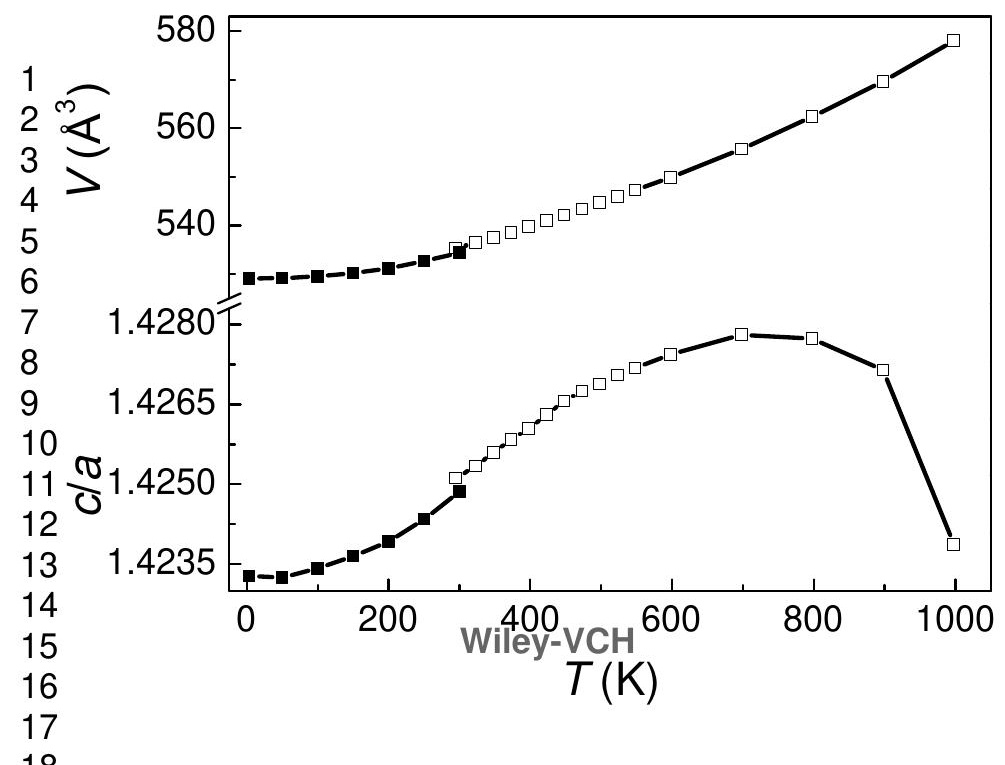


ZAAC

Page 30 of 36

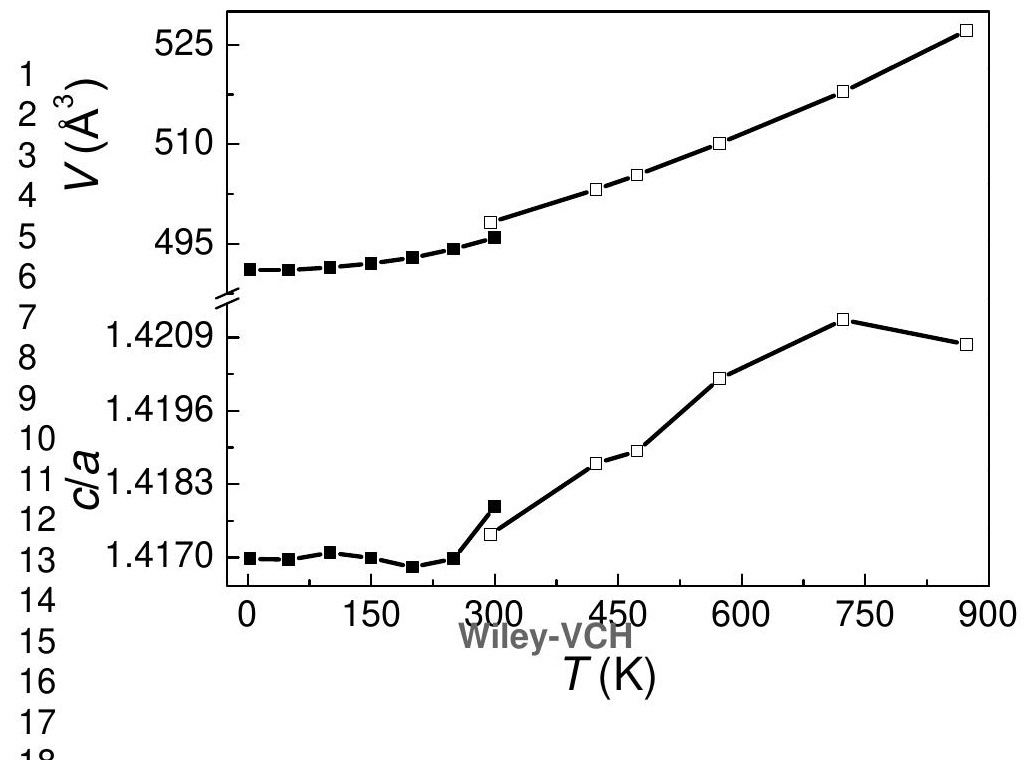


Page 31 of 36

ZAAC

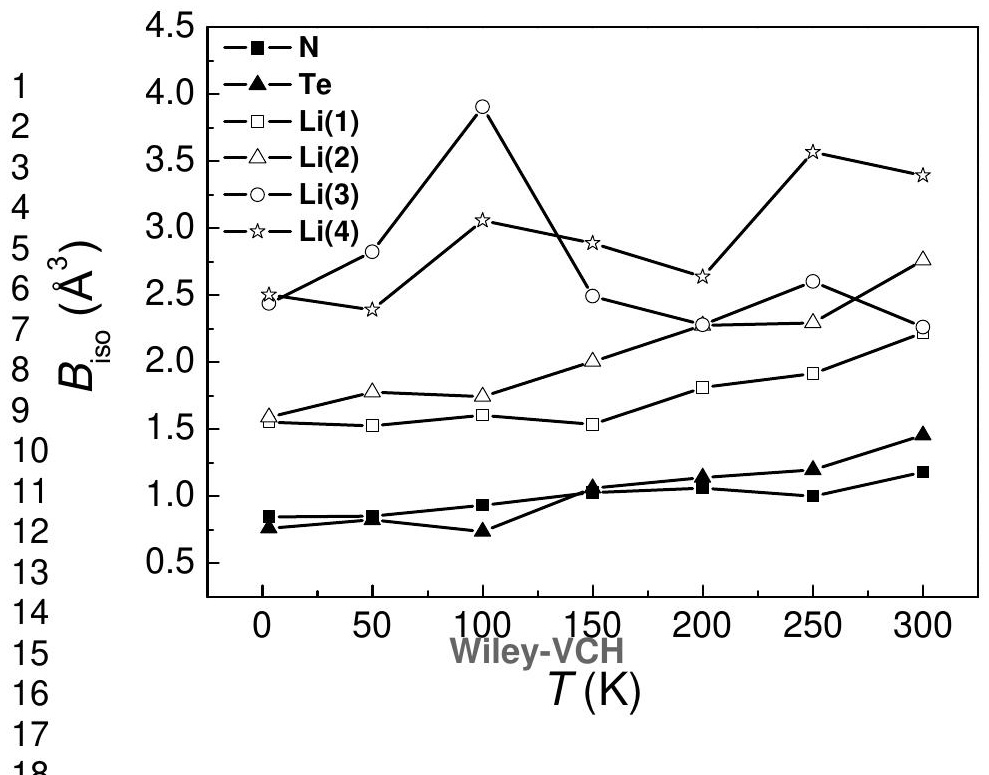


ZAAC

Page 32 of 36

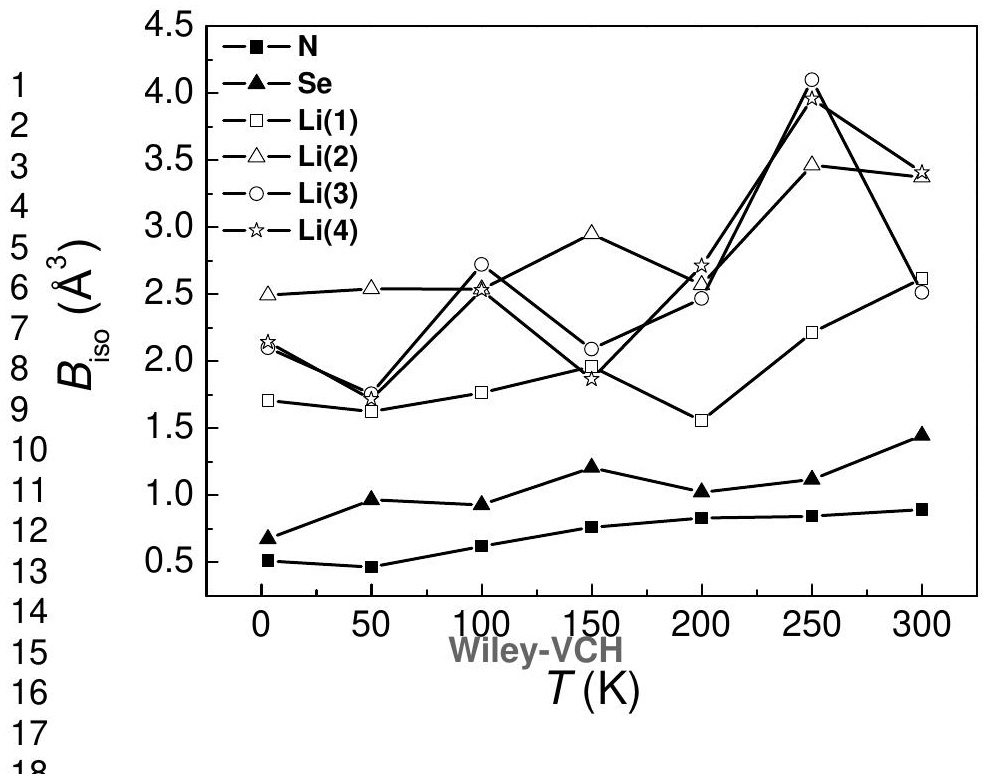




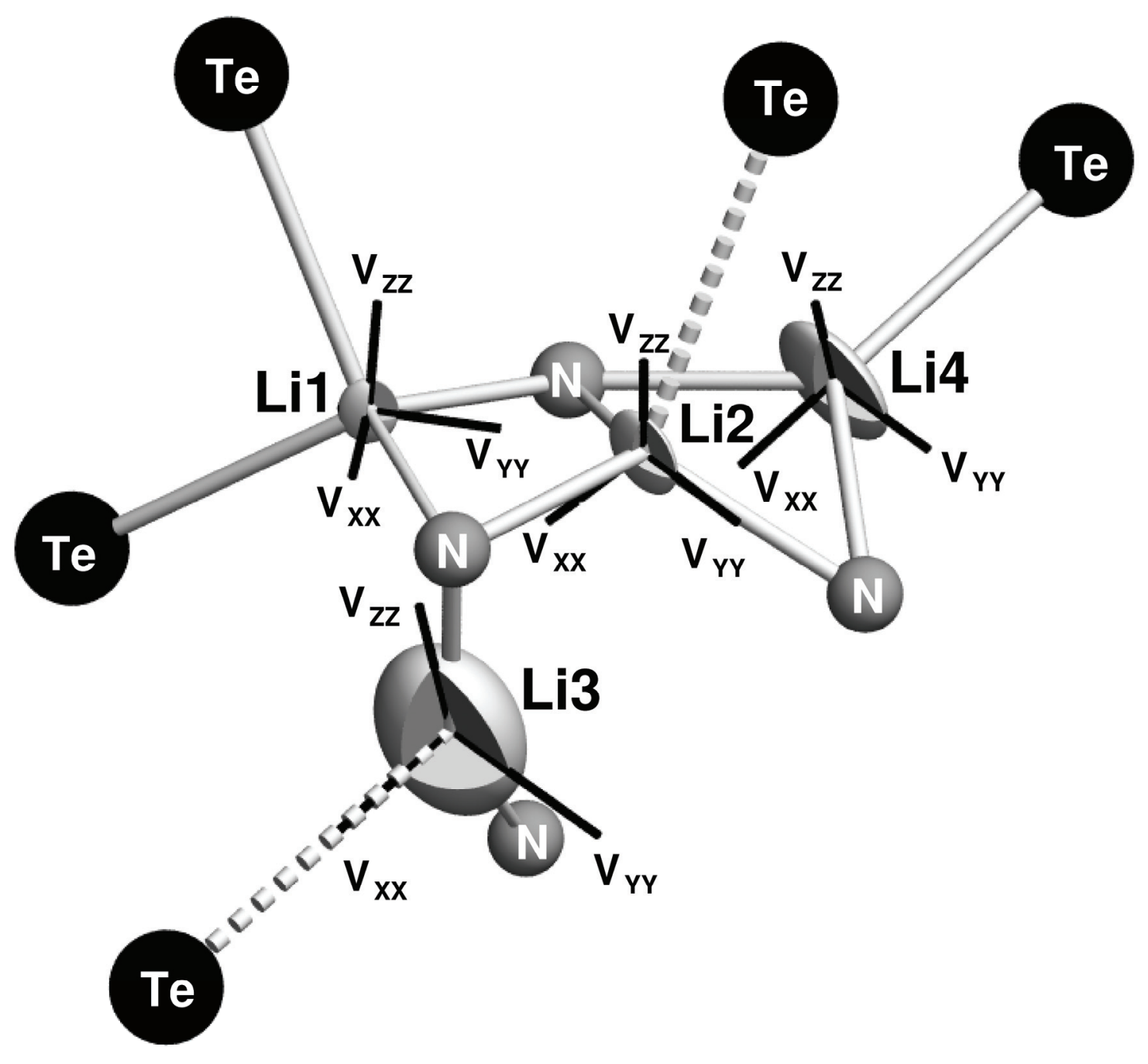




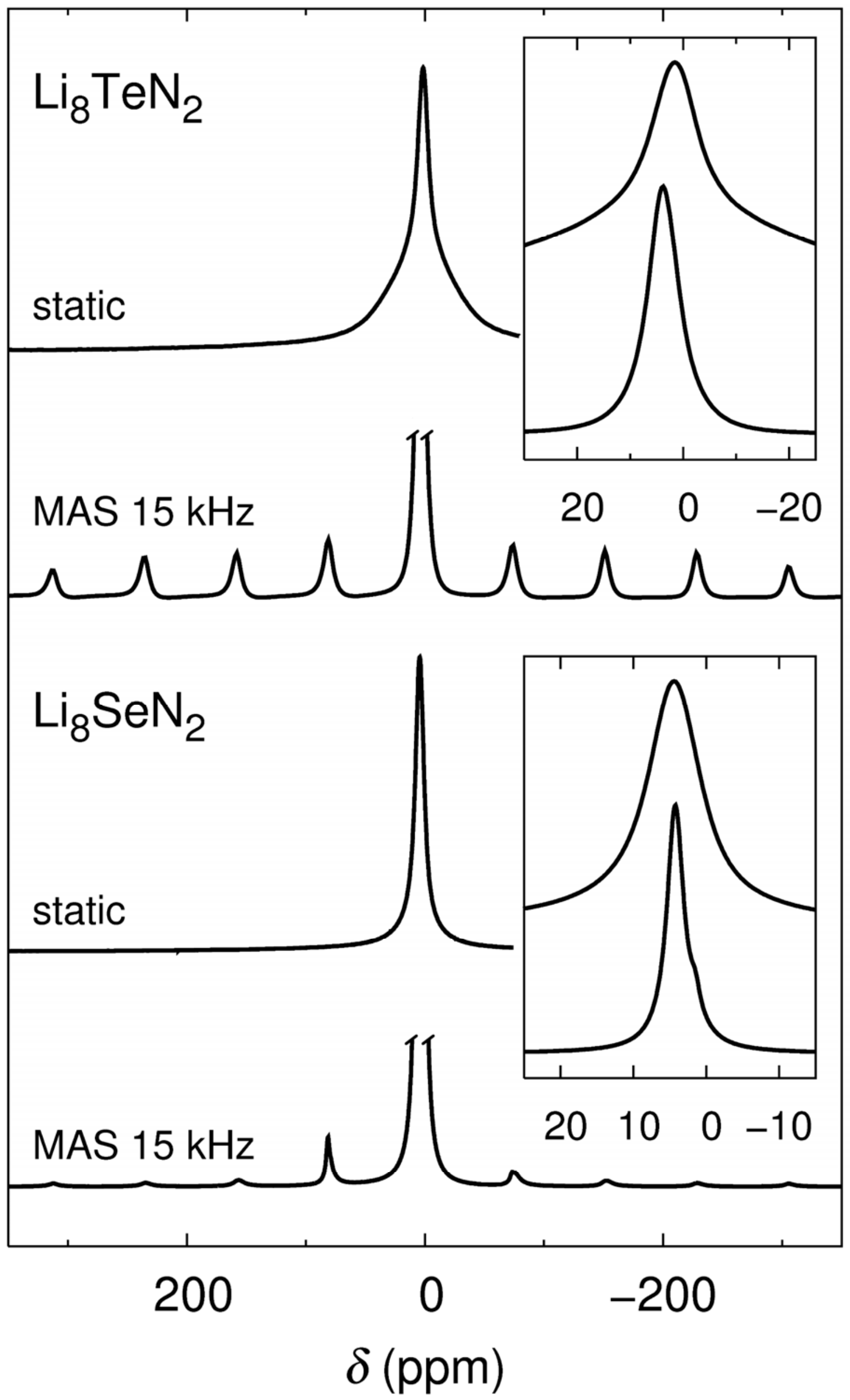

Wiley-VCH 

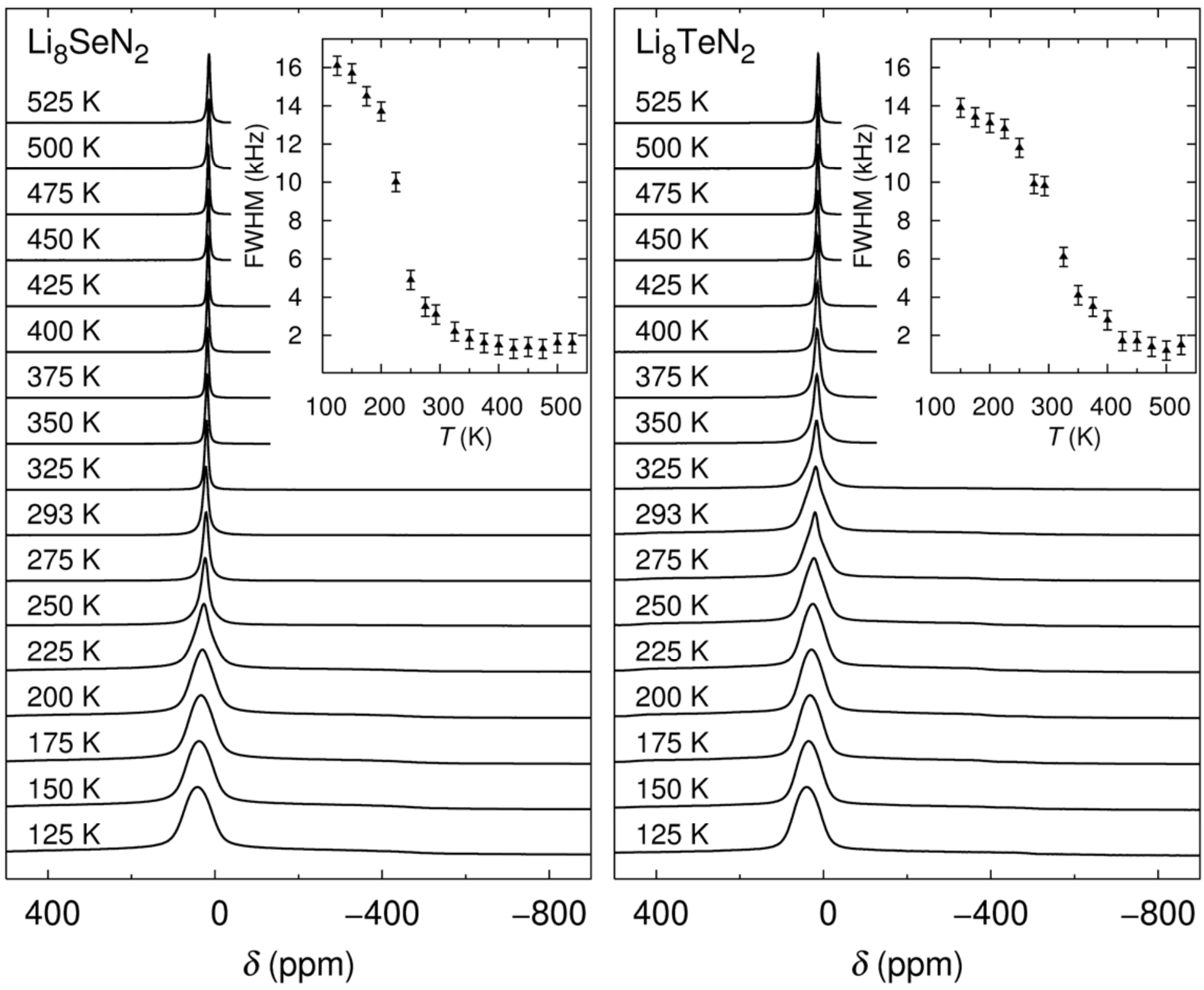


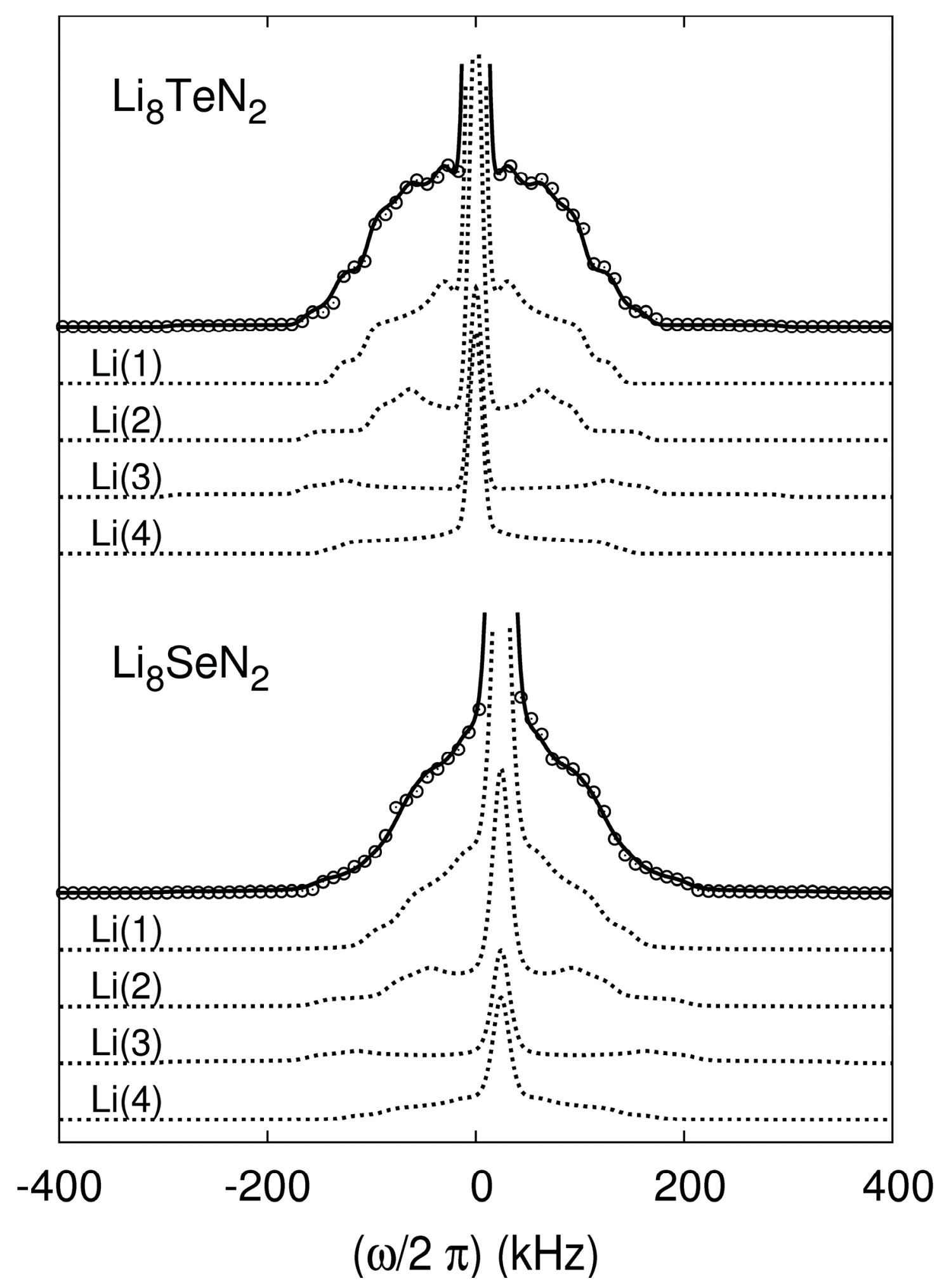

